\title{
Operando X-ray Characterization of High Surface Area Iridium Oxides to Decouple their Activity Losses for the Oxygen Evolution Reaction
}

Mauro Povia, ${ }^{1, \#}$ Daniel Abbott,,${ }^{1, \#}$ Juan Herranz,,${ }^{1, *}$ Adrian Heinritz, ${ }^{1}$ Dmitry Lebedev, ${ }^{2}$ Bae-Jung Kim, ${ }^{1}$ Emiliana Fabbri, ${ }^{1}$ Alexandra Patru, ${ }^{1}$ Joachim Kohlbrecher, ${ }^{3}$ Robin Schäublin, ${ }^{4}$ Maarten Nachtegaal, ${ }^{5}$ Christophe Copéret, ${ }^{2}$ and Thomas J. Schmidt ${ }^{1,6}$

${ }^{1}$ Electrochemistry Laboratory, Paul Scherrer Institut, 5232 Villigen, Switzerland

${ }^{2}$ Department of Chemistry and Applied Biosciences, ETH Zurich, Vladimir Prelog Weg. 1-5, CH-8093

Zurich, Switzerland

${ }^{3}$ Laboratory for Neutron Scattering, Paul Scherrer Institute, 5232 Villigen, Switzerland

${ }^{4}$ Scientific Center for Optical and Electron Microscopy, ETH Zurich, Auguste-Piccard-Hof 1, 8093

Zurich, Switzerland

${ }^{5}$ Paul Scherrer Institut, 5232 Villigen, Switzerland

${ }^{6}$ Laboratory of Physical Chemistry, ETH Zurich, 8093 Zurich, Switzerland

\# Equal contribution

*Corresponding author: juan.herranz@psi.ch

This document is the accepted manuscript version of the following article: Povia, M., Abbott, D. F., Herranz, J., Heinritz, A., Lebedev, D., Kim, B. J., ... Schmidt, T. J. (2019). Operando X-ray characterization of high surface area iridium oxides to decouple their activity losses for the oxygen evolution reaction. Energy and Environmental Science. https://doi.org/10.1039/C9EE01018A 


\title{
Broader context
}

The increasingly popular power-to-gas technology for the utilization of hydrogen as a clean energy vector involves the use of electrolyzers to convert water into $\mathrm{H}_{2}$ and $\mathrm{O}_{2}$. The oxygen evolution reaction (OER) is the least efficient among these processes, and a catalyst is required to speed up its kinetics at the high potentials (customarily $\geq 1.4 \mathrm{~V}$ vs. the reversible hydrogen electrode) at which the reaction takes place. The state-of-the-art OER-catalyst is iridium oxide, a material of extremely limited availability in the Earth's crust and that could therefore jeopardize the development of this technology in the near future. Thus, to minimize the Ir-loading in such electrolyzers, great efforts are being devoted to develop high surface area iridium oxides that achieve maximum OER activity with minimum amounts of Ir but, on the other hand, tend to suffer from a poor operative stability. In order to clarify the mechanism behind this activity loss, in this study two high surface area iridium oxides were characterized under operando conditions using a novel setup that allows the quasi-simultaneous acquisition of anomalous small angle X-ray scattering (A-SAXS) and X-ray absorption spectroscopy (XAS) data. When combined with the results derived from complementing, ex situ characterization techniques (e.g., X-ray photoelectron spectroscopy), the operando information about the catalysts' morphology and composition inferred from these synchrotron X-ray based techniques allowed to decouple the relative contributions of different instability mechanisms (i.e., Ir-loss, particle agglomeration and/or surface oxidation) to their overall deactivation.

\begin{abstract}
$\mathrm{IrO}_{2}$ is the state-of-art of $\mathrm{O}_{2}$-evolution reaction (OER) electrocatalyst implemented in proton exchange membrane electrolyzers, but in the near future iridium's ultra-low availability could threaten the successful development of this technology. To minimize this dependency, Ir-oxides with enhanced mass-specific surface areas and OER-activities are progressively being developed, but often suffer from a poorly understood deactivation under operating conditions. To understand this activity loss, in this study we used
\end{abstract}


a modified Adams' fusion method to produce an Ir-oxide with a surface area of $\approx 350 \mathrm{~m}^{2} \cdot \mathrm{g}^{-1}$ that consists of nano-disks with their surface partially covered by a layer of $\operatorname{Ir}(\mathrm{OOH})$. In order to investigate the effect of this surface oxidation state on the catalyst's reactivity and stability, a fraction of this as-synthetized sample was submitted to a second heat-treatment in air to further oxidize its surface (i.e., yielding $\mathrm{IrO}_{2}$ with $\left.\approx 250 \mathrm{~m}^{2} \cdot \mathrm{g}^{-1}\right)$. While electrochemical characterization through rotating disk electrode voltammetry unveiled that the as-synthesized catalyst features a $\approx 2$-fold larger surface-specific OER-activity than its heat-treated derivative, it also undergoes a greater loss of such activity in the course of an accelerated stress test (AST) that mimics electrolyzer startup/shutdown $(\approx 45$ vs. $\approx 30 \%$ OER-current decrease for the as-synthetized sample vs. its heat-treated derivative, respectively). Since ex situ analyses (e.g., through X-ray photoelectron spectroscopy) were not sufficient to explain this difference in stability, the operando changes in the samples' morphology and chemical composition were assessed using a recently developed apparatus that combines small angle X-ray scattering (SAXS) and X-ray absorption spectroscopy (XAS). While the XAS measurements demonstrated the compositional stability of both catalysts (i.e., oxidation state and local geometric structure), SAXS showed that the as-synthetized catalyst is made of two-dimensionally agglomerated disks that become thinner and wider in the course of the AST, whereas the heat-treated sample is composed of morphologically stable, sintered particles in the form of rough and porous agglomerates. Considering the complementary information provided by these operando and ex situ techniques, it was then possible to quantify the contributions of Ir-dissolution, surface area loss and changes in the surface oxidation state to the destabilization of both catalysts.

\section{Introduction}

Renewable energy sources are expected to become the preponderant means of energy production in the near future, but their intrinsic intermittency translates into a need to combine them with energy storage and conversion systems that can accumulate electricity during peak production or transform it into added-value 
chemicals, respectively. ${ }^{1-3}$ In this context, the increasingly popular power-to-gas conversion implies the use of renewable electricity to electrochemically split (i.e., electrolyze) water into oxygen and hydrogen, followed by the subsequent re-electrification of the latter $\mathrm{H}_{2}$ in stationary or automotive fuel cells ${ }^{4,5}-\mathrm{a}$ sustainable energy scenario that strongly relies on the extended deployment of electrolyzers, which in their better-established, alkaline form suffer from severe limitations in terms of operative current density and pressure (typically $\leq 0.5 \mathrm{~A} \cdot \mathrm{cm}_{\text {geom }}{ }^{-2}$ and $<30$ bar, respectively). ${ }^{6}$ Alternatively, proton exchange membrane (PEM) electrolyzers can routinely function at $\gg>1 \mathrm{~A} \cdot \mathrm{cm}_{\text {geom }}{ }^{-2}$ and $>30$ bar (e.g., up to 700 bar if operated in differential mode), ${ }^{7}$ and have therefore attracted considerable interest during the last decade. Nevertheless, the costs associated with the $\mathrm{H}_{2}$ produced by these devices remains $\approx 2$ - to $\approx 4$-fold above the $2 \$ \cdot \mathrm{kg}_{\mathrm{H} 2}{ }^{-1}$ target set by the U. S. Department of Energy for the refueling of fuel cell electric vehicles (FCEVs) ${ }^{6-8}$ Closing this gap will require significant improvements in these systems' operational costs, which currently constitute the main share of the $\mathrm{H}_{2}$-production expenditures and could be reduced by increasing their operational efficiency (ideally $\geq 70 \%$ of hydrogen's lower heating value of $242 \mathrm{~kJ} \cdot \mathrm{mol}^{-1}$ $[\equiv 1.25 \mathrm{~V}]){ }^{7,9}$ This key parameter is in terms preponderantly governed by the sluggish kinetics (i.e., large overpotentials) associated with the $\mathrm{O}_{2}$-evolution reaction $(\mathrm{OER})^{9,10}$ which, combined with the highly oxidative and acidic reaction environment intrinsic to PEM-electrolyzers, limits the choice of catalysts for this purpose to the iridium-based oxides $\left(\mathrm{IrO}_{\mathrm{x}}\right)$ customarily implemented in commercial devices. ${ }^{11}$ Concomitantly, as deployed electrolyzer power increases, iridium's high price and scarcity $\left(\approx 25 \$ \cdot \mathrm{g}_{\mathrm{Ir}}{ }^{-1}\right.$ and $<9 t_{\text {Ir }}$ mined per year, respectively) $)^{12,13}$ are expected to render these catalysts a significant contributor to the $\mathrm{H}_{2}$-production $\operatorname{costs}^{10}$ and to possibly jeopardize the commercialization of this technology. ${ }^{7,14}$ In this last regard, Bernt and collaborators ${ }^{9}$ have recently estimated that in order to electrolytically-produce the $\mathrm{H}_{2}$ needed for the decarbonization of the automotive sector while limiting Ir consumption to $\leq 2 \mathrm{t} \cdot \mathrm{year}^{-1}$, Irloadings in PEM-electrolyzers must be decreased to $\leq 0.01 \mathrm{~g}_{\mathrm{Ir}} \cdot \mathrm{kW}^{-1}$, which is $\approx 50$-fold below the amount implemented in current devices. 
These required reductions in the OER-overpotential and Ir-loading could be achieved by increasing the catalytic activity of Ir-oxides and/or by maximizing the number of catalytically available sites on their surfaces (i.e., the so-called electrochemical surface area, ECSA). Regarding the former possibility, the OER-activity of iridium oxides reportedly depends on their oxidation state and crystallinity, whereby the presence of quasi-amorphous, nanocrystalline $\operatorname{Ir}(\mathrm{OOH})$ is generally acknowledged to lead to a greater surface-specific OER-activity (viz. turnover frequency) than that observed for highly-crystalline catalysts exclusively containing rutile $\mathrm{IrO}_{2} \cdot{ }^{15-19}$ Moreover, a study using low-index single crystals of the crystalline $\mathrm{Ir}^{4+}$-oxide ${ }^{20}$ has revealed that their $\mathrm{O}_{2}$-evolution reactivity depends on their surface faceting, which likely explains the reported effect of particle size and shape on the OER-activity of highly-dispersed, nanoparticlebased $\mathrm{IrO}_{2}$ catalysts. ${ }^{21-23}$ As for the above-mentioned possibility to produce $\mathrm{IrO}_{\mathrm{x}}$ catalysts with enhanced ECSAs, commercially available products (e.g., Ir-blacks, $\mathrm{TiO}_{2}$-supported $\left.\mathrm{IrO}_{2}\right)^{16,24,25}$ often display relatively low surface areas of $\approx 20-40 \mathrm{~m}^{2} \cdot \mathrm{g}^{-1}$ that can customarily be exceeded in lab-scale syntheses (e.g., modified Adams' fusion, microwave-assisted) ${ }^{15,25}$ that lead to materials with $>100 \mathrm{~m}^{2} \cdot \mathrm{g}^{-1}$ and for which the upscale potential should be promptly assessed.

Beyond these considerations, these performance-determining properties also have an effect on (and are affected by) the oxide's limited operative stability, which has been partially ascribed to an OER-driven dissolution of Ir that generally becomes more relevant as the catalyst's oxidation state lowers and its crystallinity decreases. ${ }^{26-32}$ Additionally, a number of recent studies have unveiled the operando reconstruction of the catalyst surface, ${ }^{33,34}$ which can in terms affect its intrinsic OER-activity (e.g., due to a change of the surface oxidation state, vide supra) ${ }^{15,16,19,35}$ and/or lead to its agglomeration and a corresponding loss of ECSA ${ }^{31,32,36,37}$ Chiefly, these degradation mechanisms typically have a greater impact on the highly dispersed and quasi-amorphous $\operatorname{Ir}(\mathrm{OOH})$ catalyst surfaces discussed above, which as a result display a faster OER-activity fade than more crystalline $\mathrm{IrO}_{2}$ materials with lower ECSAs. ${ }^{15,38}$ To mitigate this instability, such $\operatorname{Ir}(\mathrm{OOH})$ catalysts are often submitted to a post-synthetic heat treatment in air (typically at $\geq 250{ }^{\circ} \mathrm{C}$ ) that increases their oxidation state, crystallinity and concomitant stability, if at the expense of 
a loss of OER-activity. ${ }^{28,29,39}$ Most importantly, these instability mechanisms have generally been assessed separately and, as a result, we are not aware of any studies in which their relative contribution to the Iroxide's performance loss has been decoupled and quantified.

With this motivation, in this work we have combined several operando and post-mortem characterization techniques to unveil the contribution of these mechanisms to the overall OER-activity decrease undergone by a high surface area $\mathrm{IrO}_{\mathrm{x}}$ catalyst and its air-heat-treated derivative when both are submitted to an accelerated stress test (AST) that mimics PEM-electrolyzer's intermittent operation. More precisely, we used a chloride-free Adams' fusion method ${ }^{15,40}$ to synthesize a high surface area oxide containing a large fraction of $\operatorname{Ir}(\mathrm{OOH})$, and also prepared a heat-treated derivative of this catalyst by calcining a fraction of it at $400{ }^{\circ} \mathrm{C}$; hereafter, these as-synthesized and heat-treated samples appear referred to as $\mathrm{IrO}_{\mathrm{x}}-\mathrm{AS}$ and $\mathrm{IrO}_{2}$ HT, respectively. The resulting powders displayed the electrochemical behavior expected for such materials, i.e., the initial surface-specific OER-activity was $\approx 2$-fold greater for $\mathrm{IrO}_{\mathrm{x}}-\mathrm{AS}$ vs. $\mathrm{IrO}_{2}$ - $\mathrm{HT}$, but the latter displayed a better activity retention in the course of the AST $(\approx 55 \mathrm{vs.} \approx 70 \%$, respectively). To shed light on these differences, the operando changes in composition and morphology undergone by both catalysts were assessed through X-ray absorption spectroscopy (XAS) and small-angle X-ray scattering (SAXS) using a unique setup that combines these complementary techniques. ${ }^{41}$ Ultimately, merging the results derived from these operando techniques with those obtained upon post-mortem characterization of the potential-cycled electrodes allowed for a precise quantification of the relative contribution of different deactivation mechanisms (i.e., Ir-dissolution, agglomeration and surface oxidation) to the catalysts' overall performance decay.

\section{Experimental section}

Catalysts preparation. - $\mathrm{IrO}_{\mathrm{x}}$-AS was synthesized by a modified, chloride-free Adams' fusion method. ${ }^{15,40}$ To this end, $300 \mathrm{mg}$ of $\operatorname{Ir}(\mathrm{III})$ acetylacetonate $\left(\operatorname{Ir}(\mathrm{acac})_{3}, 98 \%\right.$ Ir, Strem Chemicals) and $10 \mathrm{~g}$ of $\mathrm{NaNO}_{3}$ 
( $>99.5 \%$, Sigma Aldrich), were homogenized by grinding in an agate mortar. The powder mixture was transferred to a porcelain crucible and successively into a muffle furnace where it was heat treated in air for $30 \mathrm{~min}$ at $350{ }^{\circ} \mathrm{C} .{ }^{15} \mathrm{~A}$ fraction of this $\mathrm{IrO}_{\mathrm{x}}$-AS sample was subsequently further calcined in a tubular furnace at $400{ }^{\circ} \mathrm{C}$ in atmospheric air for $1 \mathrm{~h}$ to produce the heat-treated catalyst, $\mathrm{IrO}_{2}-\mathrm{HT}$. The choice of this heat treatment temperature was motivated by our previous work, in which a post-synthesis calcination at $600{ }^{\circ} \mathrm{C}$ led to a severe reduction in surface area (from $\approx 110$ to $\approx 30 \mathrm{~m}^{2} \cdot \mathrm{g}^{-1}$ ). ${ }^{15}$ Thus, this lower post-calcination temperature $\left(400^{\circ} \mathrm{C}\right)$ aimed at inducing a change in the catalyst's oxidation state while minimally compromising its SA (vide infra).

Catalyst ink and electrode preparation. - Catalyst ink suspensions were prepared by diluting the oxide powders in a mixture of ultrapure water $\left(18.2 \mathrm{M} \Omega \cdot \mathrm{cm}\right.$, ELGA Purelab ${ }^{\circledR}$ Ultra), isopropanol $(99.9 \%$ Chromasolv Plus ${ }^{\circledR}$ for HPLC, Sigma Aldrich) and polymer binder ( $\approx 5 \%$ Nafion ${ }^{\circledR} 117$ solution, Sigma Aldrich). The resulting mixtures were placed in an ultrasonication bath for $15 \mathrm{~min}$ in order to disperse the catalyst and Nafion ionomer. The relative ratio of the components was slightly different for rotating disk electrode (RDE) vs. operando spectroscopic flow cell measurements. For RDE, $10 \mathrm{mg}$ of catalyst were dispersed in $1 \mathrm{~mL}$ of water, $4 \mathrm{~mL}$ of isopropanol and $20 \mu \mathrm{L}$ of Nafion solution (corresponding to an ionomer-to-catalyst mass ratio of $\approx 0.09$ ). A $10 \mu \mathrm{L}$ aliquot of this ink was subsequently drop-casted on a $5 \mathrm{~mm}$ diameter glassy carbon disc (HTW - Hochtemperatur-Werkstoffe GmbH) embedded at the center of a polytetrafluoroethylene (PTFE) RDE (Pine Research Instrumentation), yielding a catalyst loading of $\approx 100 \mu \mathrm{g}_{\text {catalyst }} \cdot \mathrm{cm}_{\text {geom }}{ }^{-2}$.

Comparatively, the inks for flow cell measurements consisted of $80 \mathrm{mg}$ of catalyst, $0.64 \mathrm{~mL}$ of water, $0.48 \mathrm{~mL}$ of isopropanol and $0.32 \mathrm{~mL}$ of Nafion solution (for an ionomer-to-catalyst mass ratio of $\approx 0.2$ ). Catalyst layers for these flow cell measurements were subsequently deposited by spray coating onto a goldsputtered, pre-cut piece of conductive Kapton foil (DuPont Kapton 200RS100) with a circular, gold-free area of $4 \mathrm{~mm}$ in diameter onto which the catalyst was sprayed using a mask. The final electrodes featured catalyst loadings of $\approx 3,000$ to $\approx 5,000 \mu \mathrm{g}_{\text {IrOx }} \cdot \mathrm{cm}_{\text {geom }}{ }^{-2}$ (i.e., $\approx 30$ - to $\approx 50$-fold larger than those used in the 
RDE-tests, vide supra) which were deemed necessary in order to record high-quality XAS spectra in the transmission acquisition mode concomitant to these measurements (see Ref. 41 and the experimental details below). We note in passing that this $\mathrm{IrO}_{\mathrm{x}}$ loading corresponds to an overall deposited mass of $\approx 600 \mu \mathrm{g}$ of catalyst plus binder, which in terms accounts for $\approx 1 \%$ of the spraying substrate's mass. Thus, in order to precisely quantify the catalyst loading while accounting for small variations in the substrate weight (caused, e.g., by Kapton's moisture uptake), all weighing operations were performed using a microbalance (Mettler Toledo XPE206DR) and included the weighing of a reference substrate. Thus, each working electrode substrate was first weighed along with the equivalent reference substrate, yielding the masses $m_{\text {substrate,to }}$ and $m_{\text {reference,to, }}$, respectively. Afterwards, the sprayed electrode substrates (having been left to dry and equilibrate for $\geq 12 \mathrm{~h}$ ) and the non-sprayed reference substrate were weighed again, yielding the masses $m_{\text {electrode,t }}$ and $m_{\text {reference,t1. }}$ The catalyst mass, $m_{\text {catalyst,t1 }}$, was then calculated using Equation $1: 41$

$$
m_{\text {catalyst }, \mathrm{t} 1}=\frac{1}{1+\mathrm{ICR}} \cdot\left[m_{\text {electrode, } \mathrm{t} 1}-m_{\text {substrate, } \mathrm{t0}} \cdot\left(\frac{m_{\text {reference, } \mathrm{t} 1}}{m_{\text {reference, } \mathrm{t}}}\right)\right]
$$

where ICR corresponds to the ink's ionomer-to-catalyst ratio. Moreover, the flow cell is equipped with carbon-based counter electrodes that were prepared using equivalent procedures, on the basis of an ink of Nafion and Black Pearls ${ }^{\circledR} 2000$ carbon (Cabot Corp. - for more details refer to the Supplementary Information).

Electrochemical Tests. - All the electrochemical measurements were performed using air-equilibrated, $0.1 \mathrm{M} \mathrm{HClO}_{4}$ as the electrolyte, which was prepared using $60 \% \mathrm{HClO}_{4}($ Kanto Chemical Co., Inc.) diluted in ultrapure water $\left(18.2 \mathrm{M} \Omega \cdot \mathrm{cm}\right.$, ELGA Purelab ${ }^{\circledR}$ Ultra). For RDE tests, the $\mathrm{IrO}_{\mathrm{x}}$-loaded working electrode was mounted on a vertical shaft (Pine Research Instrumentation) and connected to a BioLogic VMP-300 potentiostat. The shaft was inserted in a standard three-electrode glass cell with a gold mesh $(99.99 \%$, Advent Research Materials) as counter electrode and a $\mathrm{Hg} / \mathrm{HgSO}_{4}$ reference electrode (Harvard Apparatus) pre-calibrated against the reversible hydrogen electrode (RHE) scale in the same electrolyte. 
The spectroelectrochemical flow cell used for operando XAS and SAXS measurements (made of PEEK) is described in detail in Ref. 42. A syringe pump (Legato 110, KD Scientific) operated at a withdrawal flow rate of $50 \mu \mathrm{L} \cdot \mathrm{min}^{-1}$ was used to continuously flow electrolyte through the cell, which was equipped with a low leak, $2 \mathrm{~mm}$ diameter $\mathrm{Ag} / \mathrm{AgCl}$ reference electrode (Harvard Apparatus) that was also pre-calibrated vs. the RHE.

Due to the excessive evolution of $\mathrm{O}_{2}$-bubbles intrinsic to the high catalyst loadings used in the spectroelectrochemical cell, OER-activity tests could only be performed in the RDE setup, and consisted of stepping the potential $(U)$ from 1.0 to $1.6 \mathrm{~V}$ vs. RHE in $20 \mathrm{mV}$ intervals while recording the current at each potential value for $1 \mathrm{~min}$; note that the latter, stable currents were subsequently used to derive the Tafel plots presented below. Additionally, cyclic voltammetry (CV) measurements and ASTs were performed in $\mathrm{RDE}$ and flow cell configurations; the former consisted of recording CVs in a potential window of 1.0 to $1.4 \mathrm{~V}$ vs. RHE at $10 \mathrm{mV} \cdot \mathrm{s}^{-1}$, whereas the ASTs were conducted by applying a square potential wave between 1.0 and $1.6 \mathrm{~V}$ vs. RHE for 500 cycles holding at each $U$-value for $10 \mathrm{~s} .{ }^{15}$ As it will be shown below, this relatively small number of cycles (motivated by beamtime availability) already leads to very significant changes in the catalysts' OER-activity and corresponding physico-chemical properties.

Operando SAXS and XAS measurements- The combined, operando SAXS and XAS measurements were performed at the SuperXAS beamline of the Swiss Light Source (SLS, Villigen, Switzerland), which operates in top-up mode at $400 \mathrm{~mA}$ and $2.4 \mathrm{GeV}$. The polychromatic beam resulting from the 2.9 Tesla magnet was collimated using a Rh-coated collimating mirror and subsequently monochromatized using a Si(111) channel-cut monochromator. A Rh-coated toroidal mirror located after the monochromator was then used to focus the beam on the beamstop located in the experimental hutch. The resulting beam size at the sample position amounted to $1000 \times 300 \mu \mathrm{m}^{2}$. The setup for combined SAXS and XAS measurements is schematically represented in Fig. S1. In brief, it consists of three gas ionization chambers and a Pt-foil reference (for absolute energy calibration) for the XAS measurement, along with an evacuated flight tube, a beam stopper, and a Pilatus 100K detector for SAXS acquisition. Following the X-ray path, the first ion 
chamber measures the intensity of the incoming beam and is followed by the sample holder / spectroelectrochemical flow cell. The flight tube and the remaining ion chambers and Pt reference foil are mounted on a mechanical platform that can be moved perpendicularly to the beam direction as to position the components for XAS or SAXS acquisition along the beam path within $\approx 2$ min. Finally, the Pilatus $100 \mathrm{~K}$ detector and beam stopper are held on a separate stage and pre-calibrated using a glassy carbon reference sample. ${ }^{43}$ The images acquired by the Pilatus $100 \mathrm{k}$ detector were processed by a Matlab-based software package provided by the SLS's Coherent X-ray Scattering group; moreover, the absolute value of the measured intensity was transformed into a cross section per area following the procedures explained in Ref. 41.

All X-ray measurements were performed at energies around the $\mathrm{Ir}_{-} \mathrm{L}_{3}$ absorption edge (at $11.215 \mathrm{keV}$ ); specifically, SAXS were acquired at 11.160 and $11.210 \mathrm{keV}$ (corresponding to wavelength values of 0.1111 and $0.1106 \AA$, respectively) using an exposition time of $1 \mathrm{~s}$, while in the XAS measurements the $\mathrm{Si}(111)$ monochromator scanned the photon energy range from 10.915 to $11.845 \mathrm{keV}$. SAXS and XAS were acquired before the beginning of the AST and every $100 U$-cycles, in all cases while holding the potential at $1.0 \mathrm{~V}$ vs. RHE.

SAXS data treatment.- The energy-dependent SAXS curves were corrected and subtracted according to the procedures reported in Ref. 41 in order to determine the corresponding anomalous small angle X-ray scattering (A-SAXS) curves, using a glassy carbon sample as the reference to calibrate the pixel detector. ${ }^{43}$ Owing to this subtractive procedure, the A-SAXS curves are exclusively related to the $\mathrm{IrO}_{\mathrm{x}}$ catalyst and are plotted as a cross section per area $\left(\left(\frac{1 d \sigma}{A d \Omega}\right)^{\operatorname{IrOx}}\right)$ vs. the module of the scattering vector $(q)$, defined as follows:

$$
q=\frac{4 \pi}{\lambda} \sin \theta
$$

where $\lambda$ is the wave length of the monochromatic $\mathrm{X}$-ray beam used for the measurement, and $2 \theta$ is the scattering angle. The cross section per area is the ratio between the X-ray photon/matter cross section 
interaction $\left(\frac{d \sigma}{d \Omega}\right)$, and the probed area of the sample $(A)$. Notably, the subtraction of the energy-dependent scattering curves intrinsic to A-SAXS has previously been used in the electrocatalysis field to separate signals from catalyst supports or co-alloyed components, ${ }^{44-47}$ in this manuscript, however, this approach is used to get rid of contributions from the electrolyte, binder and other cell components to the measured scattered signal, thus implying that the scattering profile resulting from the subtraction of the recorded, energy-dependent curves is exclusively related to the catalytic material.

The in situ A-SAXS curves recorded for both catalysts were analyzed with the SASfit software. ${ }^{48}$ More specifically, the scattering curve of the $\mathrm{IrO}_{\mathrm{x}}$-AS catalyst was fitted using a model that includes a form factor $P(q)$ and a structure factor $S(q)$, according to the Equation:

$$
\left(\frac{1 d \sigma}{A d \Omega}\right)^{\operatorname{IrOx}} \propto P(q) S(q)
$$

where $P(q)$ describes the shape and the size of the particles and $S(q)$ contains information about the particleparticle scattering interaction. After multiple attempts at fitting the A-SAXS curves, and on the basis of the catalyst's shape discussed below, the form factor of the $\mathrm{IrO}_{\mathrm{x}}$-AS sample was best described as a flat cylinder with a diameter $(D)$ larger than its thickness $(L)$, whereby the fitting model estimates a lognormal distribution of $D$ and an average $L$-value.

As for the structure factor $S(q)$, its value is equal to 1 for diluted samples, while it raises above unit (due to particle-particle attraction) for samples in which the particles are aggregated and the interparticle distance is in the same order of magnitude as the wave length of the probing radiation. ${ }^{49}$ The fitting was performed using a function that describes particle agglomeration as a mass fractal function with a Gaussian cut-off function and mass fractal dimension, $D_{\mathrm{f} .}{ }^{50,51}$ The choice of this mass fractal function is based on the fact that an agglomeration of particles resembles one single particle; in fact, fractals are self-similar structures at different size levels and the volume of the mass fractal $\left(\mathrm{V}_{\mathrm{mf}}\right)$ is proportional to the gauge size of the fractal $\left(\mathrm{r}_{0}\right)$ to the power of the fractal dimension, $V_{m f} \propto r_{0}^{D_{f}}$. Complementarily, the values of $D_{\mathrm{f}}$ range 
between 1 and 3 and correspond to mono-, bi-, or tri-dimensional particle agglomerations (for $D_{\mathrm{f}}$ values of 1, 2 or 3 , respectively). ${ }^{51}$ Chiefly, this analysis led to the conclusion that $D_{\mathrm{f}}=2$ for $\mathrm{IrO}_{\mathrm{x}}$-AS, which implies that the particles in this $\mathrm{IrO}_{\mathrm{x}}$-AS catalyst are agglomerated in the form of two-dimensional clusters (vide infra).

The $\mathrm{IrO}_{2}$-HT A-SAXS curves were fitted using two different models that provide complementary information. The first model consist of a simple linear fit to estimate the surface fractal dimension $D_{s}$ (vide infra) ${ }^{51}$ The second one is the generalized Debye, Anderson, Brumberger (gDAB) model used to measure the average size of the catalyst pores and their distribution ${ }^{52,53} \mathrm{~A}$ more detailed explanation and strict mathematical derivation of all fitting models are provided in the Supplementary Information.

$X A S$ data treatment.- All XAS data were treated using the Demeter program package, ${ }^{54}$ which included absolute energy calibration based on the simultaneously measured Pt reference foil, background subtraction, and edge step normalization. The resulting spectra are expressed in terms of the photoelectron wave vector $k$ (in units $\AA^{-1}$ ), which was obtained by assigning the photoelectron energy origin, $\mathrm{E}_{0}$, corresponding to $k=0$, to the first inflection point of the absorption edge. The resulting $\chi(k)$ functions were weighted with $k^{2}$ to compensate for the dampening of the XAFS amplitude with increasing $k$. All $\chi(k)$ functions were then Fourier transformed over a $k$ range of $3-10 \AA^{-1}$. The amplitude reduction factor, $\mathrm{S}_{0}^{2}$, was calculated using FEFF code by fitting the Pt scattering paths of metal reference foil and assuming the numbers of nearest neighbors $(\mathrm{NN})$ of the Pt face-centered cubic structure (i.e., $\mathrm{NN}=12$ ). The determined value of $\mathrm{S}_{0}^{2}=0.74$ was then used in all subsequent fits of $\mathrm{IrO}_{\mathrm{x}}-\mathrm{AS}$ and $\mathrm{IrO}_{2}-\mathrm{HT}$ while the number of nearest neighbors, bond distance, and pseudo Debye-Waller factor parameters were allowed to vary. The theoretical model used for the EXAFS fitting of the $\mathrm{IrO}_{2}$ samples was generated from the rutile-type $\mathrm{IrO}_{2}$ structure (card 84577 ICSD).

In order to directly compare the $\mathrm{IrO}_{\mathrm{x}}-\mathrm{AS}$ and $\mathrm{IrO}_{2}$ - $\mathrm{HT}$ samples, their EXAFS spectra were fitted by employing the same two-shell model based on the rutile crystal structure that we had previously used. ${ }^{15} \mathrm{In}$ 
brief, a single $\mathrm{Ir}-\mathrm{O}$ scattering path was used to describe the 6 nearest neighbor oxygen atoms in the first coordination shell and a single Ir-Ir scattering path was used for fitting the second shell. We found that the inclusion of any additional scattering paths did not improve the quality of the fit significantly and that this approach encompassed the majority of the scattering signal, which can be seen by the best fit of $\chi(\operatorname{Im})(\mathrm{cf}$. Fig. S12).

Ex situ characterization.- As-prepared and post-mortem samples were additionally characterized using ex situ techniques like $\mathrm{N}_{2}$-sorption porosimetry, high resolution transmission electron microscopy (HRTEM), selected area electron and X-ray diffraction (SAED, XRD), and X-ray photoelectron spectroscopy (XPS). The experimental details concerning these techniques and parts of the acquired results can be found in the Supplementary Information.

\section{Result and Discussion}

Structural characterization of the initial materials. - In our previous work, ${ }^{15}$ the precise control of the calcination temperature and duration of a modified, chlorine-free Adams' fusion method yielded $\mathrm{IrO}_{\mathrm{x}}$ samples with surface areas (SAs) ranging between $\approx 30$ and $\approx 150 \mathrm{~m}^{2} \cdot \mathrm{g}^{-1}$ that, in agreement with previous literature, ${ }^{15,55}$ displayed greater OER-activities and poorer stabilities as their surface area increased. Alternatively, in this study we focus our attention on an equivalent, Adams' fusion synthesized oxide $\left(\mathrm{IrO}_{\mathrm{x}}\right.$ AS) with an even larger SA of $\approx 350 \mathrm{~m}^{2} \cdot \mathrm{g}^{-1}$ (as derived from $\mathrm{N}_{2}$-sorption measurements - see the Supplementary Information $)$ and its heat-treated derivative $\left(\mathrm{IrO}_{2}-\mathrm{HT}\right)$ with an estimated $\mathrm{SA}$ of $\approx 250 \mathrm{~m}^{2} \cdot \mathrm{g}^{-1}$.

We started the characterization of these materials by performing HR-TEM measurements, and the resulting images acquired for $\mathrm{IrO}_{\mathrm{x}}-\mathrm{AS}$ and $\mathrm{IrO}_{2}-\mathrm{HT}$ are displayed in Figs. 1a and 1d, respectively. Interestingly, the $\mathrm{IrO}_{\mathrm{x}}$-AS sample consists of $\approx 2 \mathrm{~nm}$ agglomerated particles embedded in a carbon matrix that has previously been reported in other $\mathrm{IrO}_{\mathrm{x}}$-syntheses involving metalorganic precursors like the $\operatorname{Ir}(\mathrm{acac})_{3}$ used herein. ${ }^{32}$ Complementarily, in the case of the $\mathrm{IrO}_{2}$-HT powder prepared by heat-treating $\mathrm{IrO}_{\mathrm{x}}-\mathrm{AS}$ in air for $1 \mathrm{~h}$ at 
$400{ }^{\circ} \mathrm{C}$, this additional calcination step seemingly burned away this initial carbon layer. ${ }^{17}$ Moreover, unlike in $\mathrm{IrO}_{\mathrm{x}}-\mathrm{AS}$, the individual particles in $\mathrm{IrO}_{2}-\mathrm{HT}$ are highly agglomerated in the form of a rough cluster, pointing at a thermally-induced aggregation that has already been reported for such post-heat-treated materials. ${ }^{17,32}$

To further elucidate these visual differences, we resorted to XRD to verify the effect of the thermal annealing on the catalysts' crystallographic structure. While iridium oxides synthetized by this modified Adams' fusion method using first calcination temperatures $\geq 500{ }^{\circ} \mathrm{C}$ tend to crystallize in the rutile-type structure (space group $P \frac{4_{2}}{m} n m$ ), ${ }^{15}$ the powder XRD pattern of $\mathrm{IrO}_{\mathrm{x}}-\mathrm{AS}$ (prepared at $350{ }^{\circ} \mathrm{C}$, vide supra) features three broad diffraction peaks that cannot be ascribed to any known iridium compound phase (cf. Fig. 1c) - an observation that is consistent with the behavior reported in Ref. 15 for an equivalent, high SA $\mathrm{IrO}_{\mathrm{x}}$ sample that had also been prepared at this temperature. Interestingly, this XRD pattern also resembles the ones reported for Ir-oxides prepared by calcination at 300 or $350{ }^{\circ} \mathrm{C}, 15,37,56$ while other synthetic approaches including heat treatment steps at temperatures $\leq 400{ }^{\circ} \mathrm{C}$ reportedly led to amorphous materials ${ }^{57,58}$ or oxides displaying XRD patterns closer to (or even matching) that of the rutile phase..$^{37,59,60}$ This variety of results suggests that the crystallographic nature of these kind of Ir-oxides prepared at $\leq 400{ }^{\circ} \mathrm{C}$ depends on synthetic parameters other than (if including) the calcination temperature, and thus further understanding this complex crystallographic structure remains outside the scope of the current work. On the other hand, no carbon phases could be detected by XRD, indicating that the carbon layer observed in the HR-TEM images of this $\mathrm{IrO}_{\mathrm{x}}$-AS sample (cf. Fig. 1a) has an amorphous nature. Moreover, the $\mathrm{IrO}_{2}$ HT sample resulting from the second calcination at $400{ }^{\circ} \mathrm{C}$ features a diffraction pattern that matches the rutile-type crystal structure (see Fig. 1c), if with an increased intensity of the (101) peak with respect to the reference model (amcsd 0019243). ${ }^{61,62}$ Such preferential orientation had already been observed in our previous paper $^{15}$ and in other small scale powder samples submitted to post-synthetic calcination steps, ${ }^{17,32,63,64}$ whereas commercially available $\mathrm{IrO}_{\mathrm{x}}$ catalysts ${ }^{65,66}$ commonly feature diffractograms that respect the intensity ratios among peaks expected for the standard rutile compound..$^{42,43}$ 
Complementary to this, XPS measurements (which have extensively been applied to study the OERmechanism on $\mathrm{IrO}_{\mathrm{x}}$ surfaces $)^{18,65-69}$ were performed on the two catalysts processed in the form of electrodes for electrochemical testing to determine the effect of the post-synthesis heat treatment on the two catalysts' surface composition. The recorded Ir 4f spectra are displayed in Figs. S2a and S2c (for $\mathrm{IrO}_{\mathrm{x}}-\mathrm{AS}$ vs. $\mathrm{IrO}_{2}$ HT, respectively), and the surface speciation derived from their deconvolution (which was performed on the basis of the constrains discussed in the Supplementary Information and listed in Table S1) ${ }^{18,70}$ are summarized in Supplementary Fig. S3 and Table S2 and S4, respectively. Interestinglythe summary of the deconvolution results in Figs. 1f and S3 discloses that the fraction of the overall surface Ir content in a 3+ oxidation state accounts to $\approx 29$ vs. $\approx 17 \%$ for $\mathrm{IrO}_{\mathrm{x}}-\mathrm{AS}$ vs. $\mathrm{IrO}_{2}$-HT, respectively. Thus, as with the above XRD results, these X-ray photoelectron spectra are consistent with our previous observations,${ }^{15}$ whereby a high-surface area $\mathrm{IrO}_{\mathrm{x}}$ prepared at $350{ }^{\circ} \mathrm{C}$ and analogous to the $\mathrm{IrO}_{\mathrm{x}}-\mathrm{AS}$ sample in this study also displayed clear signs of the larger presence of $\operatorname{Ir}(\mathrm{OOH})$ when compared to a derivative resulting from a second calcination (i.e., equivalent to the $\mathrm{IrO}_{2}$-HT catalyst herein).

Electrochemical testing in RDE configuration. - Following this initial characterization, both catalysts were electrochemically tested in RDE configuration following the protocols described in the experimental section. Interestingly, both oxides displayed similar OER Tafel slopes of $\approx 40 \mathrm{mV} \cdot \mathrm{dec}^{-1}$ (Fig. 2b), indicating that the differences in the samples' morphology and surface oxidation state discussed above have a negligible effect on the OER-mechanism on these catalysts' surfaces. Moreover, as summarized in supplementary Table S6 and Fig. S4a, this similarity among Tafel slopes also applies when comparing these two materials and the resembling $\mathrm{IrO}_{\mathrm{x}}$-catalysts with SAs spanning between $\approx 30$ and $\approx 150 \mathrm{~m}^{2} \cdot \mathrm{g}^{-1}$ featured in Ref. 15. Additionally, this consistency among samples extends to their double layer capacitance (calculated on the basis of the $\mathrm{CVs}$ recorded at $10 \mathrm{mV} \cdot \mathrm{s}^{-1}$ in the potential range $1.0-1.4 \mathrm{~V} \mathrm{vs}$. RHE), which is linearly related to the $\mathrm{N}_{2}$-sorption SA-values of the corresponding powders (listed in Table S6) as displayed in Fig. S4c. 
Moreover, in Fig. S4b we extended this comparison among various oxides to the relation between their SAs and mass-specific OER activity values (assessed as the potential $(U)$ required to reach a mass-normalized current of $10 \mathrm{~A} \cdot \mathrm{g}_{\mathrm{IrOx}}{ }^{-1}-\mathrm{cf}$. Tables 1 and $\mathrm{S} 6$ for quantitative values). However, this did not lead to an unambiguous relation between these variables, possibly because the surface oxidation state can additionally alter the reaction kinetics - a possibility that we attempted to discriminate by resorting to the surfacenormalized OER-activity / turnover frequency (TOF), which we estimated using the following equation:

$$
\operatorname{TOF}_{1.525 \mathrm{~V}}=\frac{i_{1.525 \mathrm{~V}}}{Q_{D L}}
$$

where $i_{1.525 \mathrm{~V}}$ is the mass-normalized current measured at $1.525 \mathrm{~V}$ vs. RHE (reported in Tables 1 and S6) and $Q_{\mathrm{DL}}$ is the mass-normalized double layer charge plotted in Fig. S4c. While in this case a clear relation between SA and TOF cannot be established (see Fig. S4d), the more crystalline, $\mathrm{IrO}_{2}$-like samples prepared at temperatures $\geq 500{ }^{\circ} \mathrm{C}\left(\mathrm{IrO}_{2}-90, \mathrm{IrO}_{2}-110\right)$ or having undergone a second calcination $\left(\mathrm{IrO}_{2}-30, \mathrm{IrO}_{2}-\mathrm{HT}\right)$ display TOF-values of $0.05-0.25 \mathrm{~s}^{-1}$, whereas the two catalysts made at lower temperatures and with clear signs of the presence of $\operatorname{Ir}(\mathrm{OOH})$ on their surfaces $\left(\mathrm{IrO}_{2}-150, \mathrm{IrO}_{\mathrm{x}}-\mathrm{AS}\right)$ reach higher TOFs of $0.45-0.60 \mathrm{~s}^{-1}$.

Having assessed these initial electrochemical properties, we proceeded to perform an AST that simulates a PEM-electrolyzer operating in a startup/shutdown regime, i.e., switching the potential between values of 1.0 and $1.6 \mathrm{~V}$ vs. RHE that correspond to close-to-open-circuit vs. OER-operative conditions, respectively. As shown in Fig. 2a and listed in Table 1, after 500 potential cycles $\mathrm{IrO}_{2}$-HT retained $\approx 70 \%$ of its initial OER-activity, whereas $\mathrm{IrO}_{\mathrm{x}}-\mathrm{AS}$ only kept $\approx 55 \%$ of this original performance. As pointed out in the previous section (cf. Fig. 1a), this less stable oxide features a surface carbon layer that, as further discussed below, shall get oxidized in the course of the AST due to the high potentials ( $>>1 \mathrm{~V}$ vs. RHE) involved in the latter. Thus, to verify the possible effect of this C-layer oxidation on the AST-induced deactivation observed for $\mathrm{IrO}_{\mathrm{x}}-\mathrm{AS}$, we attempted to electrochemically oxidize this carbon and then determine the OER-activity of the resulting, C-free oxide. To this end, the amount of carbon in the as-prepared catalyst was first quantified using thermogravimetric analysis (TGA) under a continuous $\mathrm{O}_{2}$-flow; after drying the 
catalyst for $3 \mathrm{~h}$ at $100{ }^{\circ} \mathrm{C}$ (see experimental section in the Supplementary Information for details), a heating ramp up to $900{ }^{\circ} \mathrm{C}$ (see Fig. S5a) led to a $\approx 5 \%$ mass loss (cf. Fig. S5b). Assuming that all of this weight decrease were assigned to the oxidation of the catalyst surface's carbon layer, the catalyst loading of $\approx 100 \mu \mathrm{g}_{\text {catalyst }} \cdot \mathrm{cm}_{\text {geom }}{ }^{-2}$ used in the electrochemical RDE measurements would translate into a C-loading of $\approx 5 \mu \mathrm{g}_{\mathrm{C}} \cdot \mathrm{cm}_{\text {geom }}{ }^{-2}$; additionally considering a 4-electron oxidation of this carbon to $\mathrm{CO}_{2}$ (through $\mathrm{C}+2 \mathrm{H}_{2} \mathrm{O}$ $\rightarrow \mathrm{CO}_{2}+4 \mathrm{H}^{+}+4 \mathrm{e}^{-}$, the complete electro-oxidation of this carbon would require a charge of $\approx 170 \mathrm{mC} \cdot \mathrm{cm}_{\text {geom }}{ }^{-2}$. On this basis, an RDE loaded with $\approx 100 \mu \mathrm{g}_{\text {catalyst }} \cdot \mathrm{cm}_{\text {geom }}{ }^{-2}$ was submitted to a chronoamperometric (CA) treatment in which the potential was held at $1.55 \mathrm{~V}$ vs. RHE until a charge of $1700 \mathrm{mC} \cdot \mathrm{cm}_{\text {geom }}{ }^{-2}$ was reached (see Fig. S6a); notably, the choice of a charge $\approx 10$-fold larger than the one estimated above for the exclusive oxidation of the carbon layer was motivated by the fact that during the CA-step undetermined fractions of the overall charge are devoted not only to C-corrosion, but also to $\mathrm{O}_{2}$-evolution. Most importantly, no clear signs of the presence of the C-layer were found upon TEM inspection of a sample of the RDE catalyst layer having undergone this oxidative treatment (see Fig. S7, including an image of an aliquot of the $\mathrm{IrO}_{\mathrm{x}}$-AS catalyst ink for comparison), thus confirming the successful oxidation of the carbon during the CA-step. Following this important verification, this C-oxidative pretreatment was performed on several RDEs which subsequently underwent the OER polarization curve protocol described in the experimental section. As depicted in Fig. S6b, the polarization curve recorded on these CA-treated, C-free electrodes is very similar to the one acquired on the as-prepared catalyst (i.e., including the C-layer), even if the former displays a smaller current at the lower potentials recorded at the beginning of the polarization curve acquisition protocol - a mismatch that can be assigned to the additional current devoted to C-corrosion for the catalyst that has not previously undergone the discussed CAtreatment. This minor difference comes to prove that the C-layer does not have a significant effect on the catalyst's initial activity and, as a result, should also not be responsible for the instability observed for this material. 
Beyond these clarifications, $\mathrm{IrO}_{2}-\mathrm{HT}$ appears to be the most suitable OER catalyst among those prepared via the Adams' fusion method due to its exceptional balance between high activity and stability, ${ }^{15}$ which is also remarkable when compared with the stability trends reported in Ref. 15 and summarized in Fig. S8. However, despite its undeniable value, the information derived from these RDE experiments does not allow us to draw any conclusions regarding the catalysts' degradation mechanisms that could be used to formulate an approach to improve their stability. With this motivation, and inspired by previous works that have linked catalyst deactivation to changes in the oxide's composition ${ }^{15,35}$ and morphology, ${ }^{31,32,36,37}$ we then proceeded to study the evolution of these variables for these two catalysts (i.e., $\mathrm{IrO}_{\mathrm{x}}-\mathrm{AS}, \mathrm{IrO}_{2}-\mathrm{HT}$ ) following the same AST while using a combined XAS and SAXS setup that allows the operando determination of these key properties. $^{41}$

Spectroelectrochemical flow cell characterization.- Prior to conducting such synchrotron-demanding measurements, though, we decided to verify the extent of agreement between the above RDE electrochemical measurements and the behavior of the same electrocatalysts in the flow cell used for the operando SAXS and XAS measurements. Specifically, the importance of this validation was motivated by the $\approx 40$-fold greater $\mathrm{IrO}_{\mathrm{x}}$-loadings implemented in flow cell vs. $\mathrm{RDE}$ experiments, which can easily lead to an incomplete utilization of the thick catalyst layers (CLs) concomitant to the former configuration. Nevertheless, in agreement with our previous observations with carbon-supported Pt-catalysts, ${ }^{41}$ the complete utilization of the oxides' CLs was successfully confirmed on the basis of the good overlay among the mass-normalized CVs recorded in RDE vs. flow cell configurations, which are plotted in Figs. 2d and S9 (for $\mathrm{IrO}_{\mathrm{x}}-\mathrm{AS}$ vs $\mathrm{IrO}_{2}$ - $\mathrm{HT}$, respectively).

Building on this approach, we proceeded to repeat the above ASTs in the spectroelectrochemical cell while recording $\mathrm{CVs}$ to estimate the changes in the double layer capacitance every 100 potential cycles. The comparison among the cycle-dependent CVs normalized with respect to the catalysts' initial loadings in both configurations (i.e., RDE vs. flow cell) is displayed in Fig. S10, while the corresponding evolution of the double layer capacitance charges in the course of the stability tests appear plotted in Fig. 2c. The latter 
indicates that the trends in capacitance loss (which should be proportional to changes in the ECSA) for both catalysts appear to be equivalent in $\mathrm{RDE}$ and the flow cell; more precisely, the capacitive charge of $\mathrm{IrO}_{\mathrm{x}}$ AS decreased from $\approx 110$ to $\approx 90 \mathrm{C} \cdot \mathrm{g}_{\text {IrOx }}{ }^{-1}$ in the course of the AST, while in the case of $\mathrm{IrO}_{2}$-HT it remained at a quasi-constant value of $\approx 80 \mathrm{C} \cdot \mathrm{g}_{\text {IrOx }}{ }^{-1}$ during the same stability measurement. Chiefly, these results indicate that the degradation mechanisms at play in the spectroelectrochemical cell are equivalent to those in RDE measurements and, as a result, the conclusions derived from the operando measurements presented below should be extensible to the OER-activity losses inferred in the latter environment (despite the setups' differences in CL thicknesses and catalyst-to-electrolyte ratios).

$X A S$-derived changes in the catalysts' composition. - Having completed this important verification, we proceeded to perform the operando compositional and morphological characterization of the two catalysts using the combined XAS and SAXS setup presented above. Regarding the first technique, XAS' bulk sensitivity implies that the derived results are representative of the catalysts' surface on which the reactions of interest take place only if these feature a sufficiently high surface-to-total number of probed atoms (and concomitantly small particle size). This extent certainly applies for the $\mathrm{IrO}_{\mathrm{x}}-\mathrm{AS}$ sample, which displays a larger surface area and electrochemical capacitive charge than an $\mathrm{IrO}_{2}$ previously investigated in Ref. 15 (cf. $\mathrm{IrO}_{2}-150$ sample in Figure $\mathrm{S} 4$ and Table S6) for which in-situ XAS measurements were sensitive to the potential-induced surface oxidation. Notably, these surface properties (i.e., $\mathrm{N}_{2}$-sorption surface area, capacitance) are also greater for the $\mathrm{IrO}_{2}$-HT sample vs. the $\mathrm{IrO}_{2}-150$ catalyst featured in Ref. 15 (cf. Figure $\mathrm{S} 4$ and Table S6), even if the former features a larger particle size of $\approx 5 \mathrm{~nm}$ (see Figure S11) - a counterintuitive result that possibly indicates that the particles in the $\mathrm{IrO}_{2}-150$ catalyst in Ref. 15 were more agglomerated than those in the $\mathrm{IrO}_{\mathrm{x}}-\mathrm{AS}$ and $\mathrm{IrO}_{2}-\mathrm{HT}$ samples featured in this study. Moreover, for this $\mathrm{IrO}_{2}$-HT sample, one can approximate the number of $\mathrm{Ir}$ atoms at the surface by assuming a $5 \mathrm{~nm} \mathrm{IrO}_{2}$ crystal with cubic shape (i.e., $50 \times 50 \times 50 \AA^{3}$ ) and a rutile structure, ${ }^{62}$ which yields a cube with 4 facets containing 17 x 12 Ir surface atoms and 2 facets containing 12 x 12 Ir surface atoms. If one totals these up and accounts for the shared corned/edge atoms, this results in 948 surface Ir atoms; additionally considering that there 
are a total of 4384 Ir atoms in the crystal, $\approx 20 \%$ of these atoms can be found at the surface. This exercise can then be repeated for the smaller, $\approx 2 \mathrm{~nm}$ particles of the $\mathrm{IrO}_{\mathrm{x}}-\mathrm{AS}$ catalyst, for which $\approx 50 \%$ of the Ir atoms can be found at the surface. These fractions of surface Ir atoms are therefore high enough to provide the desired surface sensitivity, if keeping in mind that the XAS signals reflect an average of both bulk and surface Ir species. Finally, the particle size and $\mathrm{N}_{2}$-sorption surface area of the $\mathrm{IrO}_{2}-\mathrm{HT}$ catalyst point at a greater surface-to-total atom ratio than in the case of $\mathrm{Ni}$ - and perovskite-based oxides (with an average particle size of $\approx 10 \mathrm{~nm}$ and surface areas of $23-45 \mathrm{~m}^{2} \cdot \mathrm{g}^{-1}$, respectively) for which we have successfully tracked the potential-induced oxidation of their surfaces using in situ XAS. ${ }^{71,72}$ Thus, on the basis of these comparisons, the surface-to-total number of atoms in $\mathrm{IrO}_{\mathrm{x}}-\mathrm{AS}$ and $\mathrm{IrO}_{2}-\mathrm{HT}$ is likely sufficiently high for the corresponding XAS results to be representative of the processes occurring on their catalytically-relevant surfaces.

Following this important verification, Fig. 3c shows a comparison of the in situ X-ray absorption near-edge structure (XANES) spectra recorded while holding the potential at $1.0 \mathrm{~V}$ vs. RHE on the two catalysts at the beginning of the AST, whereby $\mathrm{IrO}_{2}-\mathrm{HT}$ displays a slightly higher white line intensity (viz. spectral maximum) than $\mathrm{IrO}_{\mathrm{x}}-\mathrm{AS}$. For $\mathrm{Ir}-\mathrm{L}_{3}$ XANES, this intensity is proportional to the probability of promoting a $2 \mathrm{p}$ electron to an unoccupied $5 \mathrm{~d}$ orbital and, as a result, it is also proportional to the samples' oxidation extent, ${ }^{17,73-76}$ thus confirming that even at this potential of $1.0 \mathrm{~V}$ vs. $\mathrm{RHE}, \mathrm{IrO}_{2}$-HT is more oxidized than $\mathrm{IrO}_{2}$-AS (consistent with the XPS results above, even if the latter were acquired at an opencircuit-equivalent potential condition). On the other hand, as shown in Figs. 3a and 3b, the XANES spectra of the two catalysts did not display significant changes as the number of cycles in the degradation protocol increased (at least within the limited resolution concomitant to these measurements), indicating that both catalysts seemingly preserved their oxidation state in the course of the AST.

Additionally, the extended X-ray absorption fine structure (EXAFS) part of the spectra were Fouriertransformed and fitted following the procedures detailed in the experimental section; these fits and the structural parameters derived from them are summarized in Fig. S12 and Tables S7 and S8. Fig. 3d displays 
the effect of the cycle number on the Ir-O bonding distances derived from these fits, which retained their initial values of $\approx 2.02$ vs. $\approx 2.00 \AA$ for $\mathrm{IrO}_{2}$-AS vs. $\mathrm{IrO}_{2}$-HT over the course of the AST. Interestingly, Ir$\mathrm{O}$ bonding distances of $\approx 2.02$ and $\approx 1.98 \AA$ have been assigned to $\mathrm{IrO}_{\mathrm{x}}$ with iridium in oxidation states of $3+$ and $4+$, respectively, ${ }^{73,74,76}$ suggesting that the average oxidation state of the samples under analysis is closer to $\operatorname{Ir}(\mathrm{OOH})$ than to $\mathrm{IrO}_{2}$. These results may appear to contradict the above XRD-characterization of the initial materials, which led to the assignment of the $\mathrm{IrO}_{2}-\mathrm{HT}$ sample to a distorted rutile $\mathrm{IrO}_{2}$ phase in a 4+ oxidation state. Nevertheless, this apparent disagreement is likely caused by the sensitivity of XAS to amorphous phases (like the surface $\operatorname{Ir}(\mathrm{OOH})$ detected by XPS, see Figs. 1f and S3) that pass unnoticed by X-ray diffraction. Additionally, the large surface-to-bulk number of atoms featured by $\mathrm{IrO}_{2}-\mathrm{HT}$ (as inferred from its high SA) implies that a large fraction of its XAS-response arises from surface atoms in direct contact with the electrolyte - a surface that, at the potential of $1.0 \mathrm{~V}$ vs. RHE at which the XAS were acquired, should be in an average oxidation state of $\approx+3.5$ that would explain the observed elongation of the Ir-O bonds. ${ }^{75}$

Finally, the XAS-results can also be used as a means to quantify Ir-dissolution, since the height of the absorption step is proportional to the absorbent (i.e., Ir) amount sampled by the X-ray beam (cf. the $\Delta \mu \mathrm{t}$ magnitude in Fig. S13a). Interestingly, when this metric is normalized with respect to its BOL value and plotted against the cycle number (see Fig. $\mathrm{S} 13 \mathrm{~b}$ ), the $\mathrm{IO}_{\mathrm{x}}$-AS sample is shown to have lost $\approx 50 \%$ of its initial Ir-content in the first 100 cycles of the AST. Such a result may appear striking when considering the comparatively smaller changes in the double layer charges observed in independent flow cell laboratory tests (see Figs. 2c, S10e and S10f), which would only be consistent with such a large loss of Ir on the basis of a concomitant (and hard to justify) change in the catalyst surface's intrinsic capacitance. Alternatively, (a fraction of) this large absorbance decrease can be attribute to a partial delamination of the specific electrode used in the spectroelectrochemical AST, likely caused by vigorous $\mathrm{O}_{2}$-evolution in the form of bubbles $^{29}$ and thus more related to the electrode's mechanical properties than to the material's intrinsic catalytic features. On the other hand, Fig. S13b additionally unveils the lack of significant Ir-dissolution 
observed for the $\mathrm{IrO}_{2}$-HT sample which, as discussed below, is in excellent agreement with the morphological stability inferred from the SAXS measurements on this catalyst.

Morphological changes assessed by A-SAXS.- Complementing the above XAS results, the A-SAXS curves provide information about the operando evolution of the samples' morphology and particle size. In agreement with the samples' disparate morphologies inferred from the TEM images in Figs. 1a and 1d, their A-SAXS curves at the beginning of the AST (displayed in Fig. 4a) are also different. In this regard, the A-SAXS curve of the $\mathrm{IrO}_{2}$-HT catalyst displays a linear shape in the $q$-range extending between $\approx 0.8$ and $\approx 3 \mathrm{~nm}^{-1}$ that is indicative of a power-law relation between the scattering cross section per area and the module of the scattering vector, as expressed by the equation: ${ }^{51}$

$$
\left(\frac{1 d \sigma}{A d \Omega}\right)^{N P-I r} \propto q^{-\alpha}
$$

whereby the slope of the double-logarithmic plot $(-\alpha)$ can be related to the surface fractal $\left(D_{\mathrm{s}}\right)$ using the expression: ${ }^{51}$

$$
\alpha=6-D_{S}
$$

Note that physically meaningful values of $D_{\mathrm{s}}$ must be limited to the range of 2 to 3 , with $D_{\mathrm{s}}=2$ being indicative of a scattering object with a smooth surface and $D_{\mathrm{s}}=3$ of a completely rough one. ${ }^{51}$ On the basis of the slope estimated for this linear range $(\alpha=3.3 \pm 0.1)$, the resulting value of the fractal surface $\left(D_{\mathrm{s}}=2.7 \pm 0.1\right)$ indicates that $\mathrm{IrO}_{2}-\mathrm{HT}$ displays a highly rough surface consistent with the porous material visualized in the TEM images in Fig. 1d and S11. Moreover, the lack of changes and systematic overlap in the A-SAXS curves of this catalyst in the course of the AST (shown in Fig. S14b) imply that this $\mathrm{IrO}_{2}-\mathrm{HT}$ sample preserves its original morphology in this stability test - a SAXS-inferred conclusion that is consistent with the quasi-identical TEM images recorded for the catalyst at the beginning- and end-of-life (BOL, EOL), which are showcased in Figs. 1d and 1e. Further information regarding the additional fitting 
of the $\mathrm{IrO}_{2}$-HT's A-SAXS curves using a gDAB model is supplied in the Supplementary Information (cf. Fig. S15 for the actual fits).

In contrast to the A-SAXS curves of $\mathrm{IrO}_{2}-\mathrm{HT}$, those recorded for the $\mathrm{IrO}_{\mathrm{x}}-\mathrm{AS}$ sample display a greater curvature along the complete $q$-range (see Fig. $4 \mathrm{a}$ ) and require a more complicated model to fit them. As reported in the experimental section and the Supplementary Information, these curves were fitted including a form factor $(P(q))$ that describes the particles as disks and the particle cluster as a Gaussian mass fractal. The choice of this disk-shape was based on the BOL-TEM picture in Fig. 1a, whereby the individual oxide particles are shown to be rounded. On the basis of this observation, a first fitting attempt assuming a spherical particle geometry was unsuccessful. In a second step, an ellipsoidal form factor was assumed in order to estimate the size of the ellipsoidal axis and, consequently, the particle anisotropy. This led to the conclusion that the nanoparticles' shape can be well represented by a disk, and this form factor resulted in the best possible fits (see Fig. S15). Moreover, the fractal dimension $\left(D_{\mathrm{f}}\right)$ value of 2 used in the fitting model, implying a 2D-agglomeration of these disk-shaped particles to form a cluster (see discussion of the A-SAXS curve fitting in the Supplementary Information), was also justified on the basis of TEMtomography measurements displayed in Fig. S16 and the video file, which show that the catalyst's agglomerates consist of two-dimensional flakes. Chiefly, this disk-like shape implies that the particles' diameter is larger than their thickness, and should not be misinterpreted with the rod-like geometry (i.e., with a length/thickness dimension greater than the diameter) observed in Ref. 15 for a series of Adams fusion-derived iridum oxides synthesized at calcination temperatures $\geq 500{ }^{\circ} \mathrm{C}$.

Unlike $\mathrm{IrO}_{2}-\mathrm{HT}$, the A-SAXS curves of $\mathrm{IrO}_{\mathrm{x}}$-AS significantly evolve over the course of the AST (see Fig. S14a), qualitatively agreeing with the severe aggregation of the material observed upon comparison of the BOL and EOL TEM images in Figs. 1a and 1b. Following the fitting of these curves (see Fig. S15), progressive U-cycling causes a narrowing of the disks' diameter distribution (cf. Fig. $4 \mathrm{~b}$ and the quantitative evolution of the width parameter and of Pearson's second coefficient in Fig. S17) accompanied by an upshift of the average diameter $(<\mathrm{D}>$, see Fig. $4 \mathrm{c})$ and a decrease of the average disk thickness $(<\mathrm{L}>$, Fig. 
$4 d)$. In other words, the trends in the variation of $\langle\mathrm{D}>$ and $\langle\mathrm{L}>$ can be explained by assuming a rearrangement of the Ir-cations inside the particle that leads to a flattening and broadening of the initial disks' shape, as schematized in the insert in Fig. 4. On the other hand, the overall crystalline structure of the IrOx-AS catalyst did not change during the AST, since no significant differences were observed upon comparison of the BOL and EOL electron diffraction patterns and corresponding integrated profiles displayed in Fig. S18 (whereby the diffraction peaks excellently overlay those measured by XRD, see Fig. 1c). Tentatively, this apparent disagreement among techniques can again be ascribed to the lack of sensitivity of diffraction techniques to the materials' amorphous domains (e.g., the $\operatorname{Ir}(\mathrm{OOH})$ phase on the catalyst's surface), which would in terms be involved in the morphological reconstruction process described herein.

Building on this analysis, Equations S5 and S6 in the Supplementary Information were used to estimate the cycle-dependent gyration radius $\left(R_{\mathrm{g}}\right)$ and average number of particles per cluster $(<\mathrm{N}>)$, respectively; the results are reported in Fig. S19, which unveils a mild loss of $\approx 2$ disks for every 100 U-cycles along with a moderate increase of $\mathrm{R}_{\mathrm{g}}$ from $\approx 8$ to $\approx 9.5 \mathrm{~nm}$ over the course of the AST. Moreover, using the average values of $<\mathrm{D}>$ and $<\mathrm{L}>$ derived from the A-SAXS fitting, the average volume $<\mathrm{V}>$ (Fig. S20) of the iridium oxide disks can be estimated with the equation:

$$
<V>=\frac{\pi<D>^{2} \cdot\langle L>}{4}
$$

and the product of $\left\langle\mathrm{V}>\right.$ times $<\mathrm{N}>$ can be considered to be equal to the average cluster volume, $<\mathrm{V}_{\text {cluster }}>$, that appears plotted as a function of the cycle number in Fig. 5a. Assuming that the cluster density remained constant along the AST, these results would point at a loss of $\approx 20 \%$ of the $\mathrm{IrO}_{\mathrm{x}}$ mass over the course of the stability test. Additionally considering that particle detachment only accounts to $\approx 2$ particles lost every 100 cycles (for an overall decrease from $\approx 56$ to $\approx 48$ particles from BOL to EOL - cf. Fig. S19a), most of this mass loss can be assigned to Ir- dissolution, concomitant to the high oxidation extents (i.e., $\geq 5+$ ) reached by Ir in the course of the OER..$^{31,68,76,77}$ 
At this stage, it is worth comparing this A-SAXS-inferred oxide-loss with the one derivable from the XASresults (cf. Fig. S13b) which, as discussed in the previous section, are likely affected by a partial delamination of the $\mathrm{IrO}_{\mathrm{x}}$-AS electrode at the beginning of the spectroelectrochmical AST. Notably, this partial catalyst detachment is not encompassed in the A-SAXS fractal analysis, which only monitors changes in the agglomerates' properties independently from their absolute mass. Thus, in the discussion of the results included below we have exclusively considered the $\approx 20 \%$ catalyst loss inferred from the ASAXS measurements, which we consider more representative of the material's intrinsic properties as opposed to the mechanical stability of the corresponding catalyst layer.

Beyond these considerations, the particle geometry and volume estimated through this A-SAXS analysis can be used to derive a corresponding, geometrical SA (plotted in Fig. 5b) using the equation:

$$
S A=\frac{\pi<D>\cdot<L>+\pi \frac{<D>^{2}}{2}}{\rho_{\text {Iro } 2} \cdot<V>}=\frac{4<L>+2<D>}{\rho_{\text {Iro2 }}<D><L>}
$$

where we assume that the density of $\operatorname{IrO}_{\mathrm{x}}-\mathrm{AS}\left(\rho_{\mathrm{IrO} 2}\right)$ is equal to that of rutile $\mathrm{IrO}_{2}\left(11.6 \mathrm{~g} \cdot \mathrm{cm}^{-3}\right)^{62}$ and (as in the $<\mathrm{V}_{\text {cluster }}>$ estimate above) that its value remains constant during the degradation protocol. Interestingly, the validity of the former assumption is confirmed by the good agreement between the BOL SA value calculated with this approach $\left(337 \pm 7 \mathrm{~m}^{2} \cdot \mathrm{g}^{-1}\right)$ and the $350 \mathrm{~m}^{2} \cdot \mathrm{g}^{-1}$ derived from $\mathrm{N}_{2}$-sorption porosimetry measurements (vide supra). Extending this procedure to the cycle-dependent geometrical parameters, the estimated SA reaches $413 \pm 9 \mathrm{~m}^{2} \cdot \mathrm{g}^{-1}$ at the end of the AST - a value that may appear high, but that remains well-below what would be expected for monolayer planes of rutile $\mathrm{IrO}_{2}$ of (101), (001) or (100) orientations, for which we have calculated SA-values of 665,764 , and $1090 \mathrm{~m}^{2} \cdot \mathrm{g}^{-1}$, respectively (using the crystallographic parameters reported by Bolzan et al., ${ }^{62}$ see Fig S21, Table S9 and the Supplementary Information for more details).

On top of allowing these SA estimates, the above $\mathrm{IrO}_{\mathrm{x}}$-mass determination can also be used to correct the double layer charges previously reported in Fig. 2c, and that appear re-plotted in Fig. 5c considering or 
ignoring the loss of cluster volume / mass reported in Fig. 5a - leading to the conclusion that this massnormalized charge $\left(Q_{\mathrm{DL}}\right)$ did not change significantly in the course of the AST. Moreover, this charge should be proportional to the catalyst's ECSA, and thus its quotient with the (geometrical) SA would yield a quantity related to the catalyst's utilization, $\left(Q_{\mathrm{DL}} / \mathrm{SA}\right)_{\text {cycle. }}$. This magnitude can in terms be normalized with respect to its BOL-value, yielding a normalized utilization that can be estimated with the equation:

$$
\text { Normalized utilization }=\frac{\left({ }^{Q_{D L}} / S A\right)_{c y c l e}}{\left({ }^{Q_{D L}} / S A\right)_{B O L}}
$$

The cycling-dependent changes in this normalized utilization are then plotted in Fig. 5d, which shows that the catalyst undergoes a utilization loss of $\approx 15 \%$ in the course of the AST that is consistent with the agglomeration discussed above and inferred from the TEM images in Figs. 1a and 1b.

Linking operando results and the catalysts' OER-activity loss.- Having quantified these changes in the catalysts' utilization and mass on the basis of the A-SAXS results, we now attempt to bridge these operando results with the OER-activity decrease observed in RDE measurements. As highlighted above, this approach strongly relies on the good agreement among double layer capacitance losses in each configuration (i.e., RDE vs. flow cell) showcased in Fig. 2c and S10, and assumes that such consistency would extend to the trends in the materials' catalytic performance loss (which we could only assess in the RDE configuration - cf. Experimental Section above). To this end, we start by assuming that the OERkinetics on $\mathrm{IrO}_{\mathrm{x}}$ can be described according to the Butler-Volmer equation, following the formalism:

$$
i_{O E R}=i_{0} \cdot L_{I r O x} \cdot E C S A \cdot e^{\frac{\alpha F}{R T} \eta}
$$

where $i_{\mathrm{OER}}$ and $i_{0}$ are the OER- and exchange-current densities, respectively, $L_{\mathrm{IrOx}}$ refers to the oxide loading, $\alpha$ is the transfer coefficient, $F$ stands for the Faraday constant, $R$ and $T$ are the gas constant and temperature, and $\eta$ refers to the overpotential. Normalizing the cycle-dependent OER-current with respect to its BOL- 
value while assuming that the OER-mechanism (related to the transfer coefficient within the equation's exponential term) remained unchanged along the AST, the following expression can be derived:

$$
\frac{i_{O E R, c y c l e}}{i_{O E R, B O L}}=\frac{i_{0, c y c l e}}{i_{0, B O L}} \cdot \frac{L_{I r O x, c y c l e}}{L_{I r O x, B O L}} \cdot \frac{E C S A_{\text {cycle }}}{E C S A_{B O L}}
$$

whereby the quotient between cycle-dependent and BOL OER-currents is equivalent to the normalized OER-activity retention plotted in Fig. $2 \mathrm{a}$, which for $\mathrm{IrO}_{\mathrm{x}}-\mathrm{AS}$ accounted to $\approx 55 \%$ by the end of the AST. Moreover, for the same catalyst, the ratios between EOL and BOL oxide loadings can be ascribed to the cluster volume / mass retention derived from the SAXS results presented above (cf. Fig. 5a), which is equal to $\approx 80 \%$. Finally, as also discussed in the previous section, the cycling-induced changes in ECSA are negligible for this catalyst once this loss of Ir is taken into consideration (i.e., $\mathrm{ECSA}_{\mathrm{EOL}} \approx \mathrm{ECSA}_{\mathrm{BOL}}$, see Fig. 5c).

Inputting these values into Equation 11 leads us to the conclusion that, in order to justify the OER-activity loss reported in Fig. 2a, the intrinsic exchange current density ascribed to $\mathrm{IrO}_{\mathrm{x}}-\mathrm{AS}$ had to decrease by $\approx 30 \%$ during the AST (i.e., $i_{0, \mathrm{EOL} .1} / i_{0, \mathrm{BOL}} \approx 0.7$ ). This loss of exchange current density is likely related to changes in the sample' surface reactivity, which in terms stem from the decrease in the surface content of the more OER-active, amorphous $\operatorname{Ir}(\mathrm{OOH})$ component inferred from the post-mortem XPS results showcased in Figs. 1f and S2b (cf. the deconvolution results in Tables S2 and S3, summarized in Fig. S3). Specifically, the latter figure showcases a $\approx 3$-fold decrease in the catalyst's $\operatorname{Ir}^{3+}$ surface content (from $\approx 29$ to $\approx 8 \%$ of the overall Ir-concentration) at the expense of the formation of more $\operatorname{Ir}^{4+}$ (cf. Fig. S3) that is consistent with recent post-mortem XPS studies reporting an increase in the oxidation extent of $\mathrm{IrO}_{\mathrm{x}}$ in the course of stability measurements; ${ }^{16,19,35}$ chiefly, this good agreement applies in spite of the differences among the potential-switching AST applied herein and the galvanostatic hold stability tests used in those works. On the other hand, these XPS-results may appear to contradict our previous operando XAS measurements, which indicated that $\mathrm{IrO}_{\mathrm{x}}$-AS remained in $\mathrm{a} \approx 3+$ oxidation state in the course of the AST (see Figs. 3a and 3d, along with the qualitatively similar results reported in Ref. 15 for an equivalent 
sample). As in the case of the $\mathrm{IrO}_{2}$-HT's EXAFS-results discussed above, though, this apparent discrepancy possibly arises from the low potential applied during the acquisition of the X-ray absorption spectra (i.e., $1.0 \mathrm{~V}$ vs. RHE), which drives the reduction of the oxide towards an oxidation state lower than the one it would have in the open circuit potential (OCP)-analogous condition representative of ex situ XPS measurements..$^{73,74}$

Finally, the quantitative analysis applied above can also be extended to the $\mathrm{IrO}_{2}-\mathrm{HT}$ sample, for which we observed $\mathrm{a} \approx 30 \%$ loss of OER activity in the course of the AST (cf. Fig. 2a), but that did not undergo any changes in composition or morphology inferable from (operando) XAS and SAXS (i.e., the BOLnormalized loading- and ECSA-quotients in above Equation 11 remained equal to 1 for this catalyst). As a result, this deactivation must be exclusively caused by a decrease of the oxide's intrinsic reactivity, yielding a value of $\approx 0.7$ for the $i_{0, \mathrm{EOL}} / i_{0, \mathrm{BOL}}$ quotient in Eq. 11 that matches the one estimated for $\mathrm{IrO}_{\mathrm{x}}-\mathrm{AS}$ (vide supra). Moreover, as in the latter case, this OER-activity drop is again accompanied by a resembling, $\approx 2$-fold decrease in the surface concentration of $\mathrm{Ir}^{3+}$ species inferred from (post-mortem) XPS measurements (from $\approx 17$ to $\approx 10 \%$ of the overall Ir surface concentration, see Figs. 1f, S2d and S3). Beyond this consistency among samples, this result additionally implies that, in the absence of significant bulk-compositional and morphological changes (i.e., as in the case of $\mathrm{IrO}_{2}-\mathrm{HT}$ ), the progressive oxidation of the catalyst's surface represents the main cause for its concomitant deactivation, and should be minimized in order to further improve the stability of such materials.

\section{Conclusions}

In summary, the combination of various operando and ex situ characterization techniques presented in this study has allowed to quantitatively decouple the contributions of different degradation mechanisms to the overall instability displayed by a high surface area iridium oxide and its heat-treated derivative $\left(\mathrm{IrO}_{\mathrm{x}}\right.$ - $\mathrm{AS}$ vs. $\mathrm{IrO}_{2}-\mathrm{HT}$, respectively). In agreement with previous studies, the lower oxidation extent of the $\mathrm{IrO}_{\mathrm{x}}-\mathrm{AS}^{\prime} \mathrm{s}$ 
surface inferred from XPS and in situ XAS translated into an initially higher surface- and mass-specific OER-activity that, on the other hand, was accompanied by a poorer stability in an AST that mimics PEMelectrolyzer startup/shutdown. To shed light on the reasons for the observed difference in durability, we resorted to a setup in which SAXS and XAS are combined to study the operando changes in a sample's morphology and composition. Whereas the XAS measurements indicated that the samples' composition remained stable during the AST, the fractal analysis of the A-SAXS results unveiled that the $\mathrm{IrO}_{\mathrm{x}}$-AS sample is composed of disk-shaped particles assembled in a two-dimensional structure that lose $\approx 20 \%$ and $\approx 15 \%$ of their initial iridium oxide mass and surface utilization in the course of the AST, respectively. Complementarily, the in situ A-SAXS curves of the $\mathrm{IrO}_{2}-\mathrm{HT}$ sample did not change during the AST, thus disclosing this catalyst's excellent morphological stability. By substituting the above losses into a normalized form of the Butler-Volmer equation, we estimated that both catalysts suffer from $\mathrm{a} \approx 30 \% \operatorname{loss}$ of surface-specific, intrinsic OER-activity that was ascribed to the AST-induced oxidation of their surface inferred from post-mortem XPS measurements.

Chiefly, these results provide unprecedented and greatly needed insight regarding the relative contributions of the different degradation mechanisms postulated in the literature to the overall instability undergone by these materials. Specifically, the minimization of the Ir-dissolution and agglomeration achieved through post-synthetic calcination should be complemented by strategies to minimize the operando oxidation of the catalyst surface. Considering that the latter is linked to the operative (over)potential, further enhancements in the catalysts' ECSA and/or intrinsic OER-activity (i.e., $i_{0}$ ) appear as the best approach to minimize this effect, but should not imply the presence of excessively unstable $\operatorname{Ir}(\mathrm{OOH})$. Alternatively, to fulfill these requirements, further synthetic efforts should be devoted to produce more oxidized, high surface area $\operatorname{IrO}_{\mathrm{x}}$ with preferentially-oriented, highly-active $\mathrm{IrO}_{2}$ surface facets (e.g., (100) domains). ${ }^{20}$ 


\section{Conflicts of interest}

There are no conflicts to declare

\section{Acknowledgments}

We are grateful to Mr. Christian Marmy and Mr. Urs Vogelsang for their technical support. We want to thank Dr. Jens J. Eller, Dr. Claire Villevieille and Dr. Juliette M. Billaud for allowing us to use their laboratory equipment, Dr. Tobias Binninger for his help during the preparation and completion of the beamtime, Dr. Jan Ilavsky for providing the calibrated glassy carbon used in the SAXS measurements, Dr. Ana Diaz for her assistance in the use of the Matlab software for the SAXS data analysis, and Mr. Jonathan Halter, Mr. Mateusz Zlobinski and Mr. Henninen Trond for their help with video formatting. We are also grateful to the ScopeM (ETH Zurich) for the use of their microscopy facilities, and to the SLS for providing the beamtime needed to validate the SAXS/XAS setup and to complete the measurements displayed herein. The authors are also grateful to Dr. Viktor Wolf and Dr. Daniel Herein of Umicore AG for providing the rutile $\mathrm{IrO}_{2}$ powder used as a reference for XPS spectral deconvolution. This work was funded by the Swiss Federal Office of Energy through contract number SI/501602-01. J.H. greatly acknowledges the Swiss National Science Foundation for financial support through Ambizione Energy grant PZENP2_173632. T.J.S. thanks Innosuisse and the Swiss Competence Center for Energy Research Heat \& Electricity Storage.

\section{Author contributions}

D.A., M.P., E.F. and J.H. conceived the experiments. D.L. synthesized the catalysts and performed $\mathrm{N}_{2}-$ sorption measurements. D.A. and M.P. carried out the electrochemical tests. B.K., M.P. and R.S. performed (tomographic) microscopy and electron diffraction measurements. M.P. acquired and analyzed the X-ray diffractograms. D.A., M.P., E.F., A.P. and J.H. completed the operando SAXS and XAS measurements. 
D.A. and M.N. analyzed the XAS results. M.P. and J.K. treated the SAXS results. A.H. and J.H. acquired and analyzed the XPS results. J.H., M.P. and D.A. wrote the manuscript. All authors discussed the manuscript and participated in the finalization of the text and Figures.

\section{References}

1 M. Beaudin, H. Zareipour, A. Schellenberg and W. Rosehart, Energy Storage Smart Grids Plan. Oper. Renew. Var. Energy Resour., 2014, 14, 1-33.

2 I. Hadjipaschalis, A. Poullikkas and V. Efthimiou, Renew. Sustain. Energy Rev., 2009, 13, $1513-$ 1522.

3 J. Andrews and B. Shabani, Int. J. Hydrogen Energy, 2012, 37, 6-18.

4 U. Eberle, B. Müller and R. von Helmolt, Energy Environ. Sci., 2012, 5, 8780-8798.

5 F. N. Büchi, M. Hofer, C. Peter, U. D. Cabalzar, J. Bernard, U. Hannesen, T. J. Schmidt, A. Closset and P. Dietrich, RSC Adv., 2014, 4, 56139-56146.

6 M. Carmo, D. L. Fritz, J. Mergel and D. Stolen, Int. J. Hydrogen Energy, 2013, 38, 4901-4934.

7 U. Babic, M. Suermann, F. N. Büchi, L. Gubler and T. J. Schmidt, J. Electrochem. Soc., 2017, 164, F387-F399.

$8 \quad$ U.S. Office of Energy Efficiency and Renuwable Energy, Fuel Cell Technologyes Office MultiYear Research, Development, and Demonstration Plan, https://www.energy.gov/eere/fuelcells/downloads/fuel-cell-technologies-office-multi-yearresearch-development-and-22, (accessed January 31, 2019).

9 M. Bernt, A. Siebel and H. A. Gasteiger, J. Electrochem. Soc., 2018, 165, F305-F314.

10 M. Suermann, T. J. Schmidt and F. N. Büchi, Electrochim. Acta, 2016, 211, 989-997.

11 E. Fabbri, A. Habereder, K. Waltar, R. Kötz and T. J. Schmidt, Catal. Sci. Technol., 2014, 4, 3800-3821.

12 Johnson Matthey, http://www.platinum.matthey.com/\#, (accessed February 14, 2019).

13 P. C. K. Vesborg and T. F. Jaramillo, RCS Adv., 2012, 2, 7933-7947.

14 J. Herranz, J. Durst, E. Fabbri, A. Patru, X. Cheng, A. A. Permyakova and T. J. Schmidt, Nano Energy, 2016, 29, 4-28.

15 D. F. Abbott, D. Lebedev, K. Waltar, M. Povia, M. Nachtegaal, E. Fabbri, C. Copéret and T. J. Schmidt, Chem. Mater., 2016, 28, 6591-6604.

16 X. Tan, J. Shen, N. Semagina and M. Secanell, J. Catal., 2019, 371, 57-70. 
A. Minguzzi, C. Locatelli, O. Lugaresi, E. Achilli, G. Cappelletti, M. Scavini, M. Coduri, P. Masala, B. Sacchi, A. Vertova, P. Ghigna and S. Rondinini, ACS Catal., 2015, 5, 5104-5115.

V. Pfeifer, T. E. Jones, J. J. Velasco Vélez, C. Massué, M. T. Greiner, R. Arrigo, D. Teschner, F. Girgsdies, M. Scherzer, J. Allan, M. Hashagen, G. Weinberg, S. Piccinin, M. Hävecker, A. KnopGericke and R. Schlögl, Phys. Chem. Chem. Phys., 2016, 18, 2292-2296.

19 H. Yu, N. Danilovic, Y. Wang, W. Willis, A. Poozhikunnath, L. Bonville, C. Capuano, K. Ayers and R. Maric, Appl. Catal. B Environ., 2018, 239, 133-146.

K. A. Stoerzinger, L. Qiao, M. D. Biegalski and Y. Shao-horn, J. Phys. Chem. Lett., 2014, 5, 1636-1641.

J.-M. Hu, H.-M. Meng, J.-Q. Zhang, J.-X. Wu, D.-J. Yang and C.-N. Cao, J. Mater. Sci. Lett., 2001, 20, 1353-1355.

J. M. Hu, H. M. Meng, J. Q. Zhang and C. N. Cao, Corros. Sci., 2002, 44, 1655-1668.

W. Xu, G. M. Haarberg, S. Sunde, F. Seland, A. P. Ratvik, E. Zimmerman, T. Shimamune, J. Gustavsson and T. Åkre, J. Electrochem. Soc., 2017, 164, F895-F900.

E. Oakton, D. Lebedev, M. Povia, D. F. Abbott, E. Fabbri, A. Fedorov, M. Nachtegaal, C. Copéret and T. J. Schmidt, ACS Catal., 2017, 7, 2346-2352.

S. M. Alia, K. E. Hurst, S. S. Kocha and B. S. Pivovar, J. Electrochem. Soc., 2016, 163, F3051F3056.

N. Danilovic, R. Subbaraman, K. Chang, S. H. Chang, Y. J. Kang, J. Snyder, A. P. Paulikas, D. Strmcnik, Y. Kim, D. Myers, V. R. Stamenkovic and N. M. Markovic, J. Phys. Chem. Lett., 2014, 5, 2474-2478.

S. Cherevko, S. Geiger, O. Kasian, N. Kulyk, J. Grote, A. Savan, B. Ratna, S. Merzlikin, B. Breitbach, A. Ludwig and K. J. J. Mayrhofer, Catal. Today, 2016, 262, 170-180.

S. Geiger, O. Kasian, B. R. Shrestha, A. M. Mingers, K. J. J. Mayrhofer and S. Cherevko, J. Electrochem. Soc., 2016, 163, F3132-F3138.

S. Cherevko, S. Geiger, O. Kasian, A. Mingers and K. J. J. Mayrhofer, JEAC, 2016, 774, 102-110.

30 S. Cherevko, T. Reier, A. R. Zeradjanin, Z. Pawolek, P. Strasser and K. J. J. Mayrhofer, Electrochem. commun., 2014, 48, 81-85.

31 C. Spöri, J. Tai, H. Kwan, A. Bonakdarpour, D. P. Wilkinson and P. Strasser, Angew. Chemie Int. Ed., 2017, 56, 5994-6021.

32 P. Jovanovič, N. Hodnik, F. Ruiz-Zepeda, I. Arčon, B. Jozinović, M. Zorko, M. Bele, M. Šala, V. S. Šelih, S. Hočevar and M. Gaberšček, J. Am. Chem. Soc., 2017, 139, 12837-12846.

33 G. Chen, Z. Hu, Y. Zhu, B. Gu, Y. Zhong, H.-J. Lin, C.-T. Chen, W. Zhou and Z. Shao, Adv. Mater., 2018, 30, 1804333.

34 Y. Zhu, H.-C. Chen, C.-S. Hsu, T.-S. Lin, C.-J. Chang, S.-C. Chang, L.-D. Tsai, H. M. Chen, ACS Energy Lett. 2019, 4, 987-994. 
35 T. Li, O. Kasian, S. Cherevko, S. Zhang, S. Geiger, C. Scheu, P. Felfer, D. Raabe, B. Gault and K. J. J. Mayrhofer, Nat. Catal., 2018, 1, 300-305.

36 G. Li, H. Yu, X. Wang, S. Shucheng, Y. Li, Z. Shao and B. Yi, Phys. Chem. Chem. Phys., 2013, 15, 2858-2866.

37 S. Siracusano, V. Baglio, A. Stassi, R. Ornelas, V. Antonucci and A. S. Arico, Int. J. Hydrogen Energy, 2011, 36, 7822-7831.

38 C. Massué, V. Pfeifer, M. van Gastel, J. Noack, G. Algara-siller, C. Sébastien and R. Schlögl, ChemSusChem, 2017, 10, 4786-4798.

M. Vuković, J. Appl. Electrochem., 1987, 17, 737-745.

C. Felix, T. Maiyalagan, S. Pasupathi, B. Bladergroen and V. Linkov, Micro Nanosyst., 2012, 4, $186-191$.

M. Povia, J. Herranz, T. Binninger, M. Nachtegaal, A. Diaz, J. Kohlbrecher, D. F. Abbott, B. J. Kim and T. J. Schmidt, ACS Catal., 2018, 8, 7000-7015.

T. Binninger, E. Fabbri, A. Patru, M. Garganourakis, J. Han, D. F. Abbott, O. Sereda, R. Kötz, A. Menzel, M. Nachtegaal and T. J. Schmidt, J. Electrochem. Soc., 2016, 163, H906-H912.

F. Zhang, J. Ilavsky, G. G. Long, J. P. G. Quintana, A. J. Allen and P. R. Jemian, Metall. Mater. Trans. A, 2010, 41, 1151-1158.

C. Yu, S. Koh, J. E. Leisch, M. F. Toney and P. Strasser, Faraday Discuss., 2009, 140, 283-296.

C. Yu, E. F. Holby, R. Yang, M. F. Toney, D. Morgan and P. Strasser, ChemCatChem, 2012, 4, 766-770.

X. Tuaev, S. Rudi, V. Petkov, A. Hoell and P. Strasser, ACS Nano, 2013, 7, 5666-5674.

X. Tuaev, J. P. Paraknowitsch, R. Illgen, A. Thomas and P. Strasser, Phys. Chem. Chem. Phys., $2012,4,6444-6447$.

48 I. Breßler, J. Kohlbrecher and A. F. Thünemann, J. Appl. Crystallogr., 2015, 48, 1587-1598.

J. S. Pedersen, Adv. Colloid interface Sci., 1997, 70, 171-210.

T. Li, A. J. Senesi and B. Lee, Chem. Rev., 2016, 116, 11128-11180.

D. W. Schaefer and K. D. Keefer, Phys. Rev. Lett., 1986, 56, 2199-2202.

P. Debye, H. R. Anderson and H. Brumberger, J. Appl. Phys., 1957, 28, 679-683.

R. Andersson, L. F. Van Heijkamp, I. M. De Schepper and W. G. Bouwman, J. Appl. Crystallogr., 2008, 41, 868-885.

B. Ravel and M. Newville, J. Synchrotron Radiat., 2005, 12, 537-541. 
G. C. da Silva, N. Perini and E. A. Ticianelli, Appl. Catal. B, 2017, 218, 287-297.

M. Bernicke, E. Ortel, T. Reier, A. Bergmann, J. Ferreira de Araujo, P. Strasser and R. Kraenhert, ChemSusChem, 2015, 8, 1908-1915.

8 R. D. L. Smith, B. Sporinova, R. D. Fagan, S. Trudel and C. P. Berlinguette, Chem. Mater., 2014, 26, 1654-1659.

J. C. Cruz, V. Baglio, S. Siracusano, R. Ornelas, L. Ortiz-Frade, L. G. Arriaga, V. Antonucci and A. S. Aricò, J. Nanopart. Res., 2011, 13, 1639-1646.

J. Cheng, H. Zhang, H. Ma, H. Zhong and Y. Zou, Electrochim. Acta, 2010, 55, 1855-1861.

R. T. Downs and M. Hall-Wallace, Am. Mineral., 2003, 88, 247-250.

A. A. Bolzan, C. Fong, B. J. Kennedy and C. J. Howard, Acta Crystallogr. Sect. B Struct. Sci., 1997, 53, 373-380.

N. Yoshinaga, W. Sugimoto and Y. Takasu, Electrochim. Acta, 2008, 54, 566-573.

G. Li, H. Yu, W. Song, M. Dou, Y. Li, Z. Shao and B. Yi, ChemSusChem, 2012, 5, 858-861.

V. Pfeifer, T. E. Jones, J. J. Velasco Vélez, C. Massué, R. Arrigo, D. Teschner, F. Girgsdies, M. Scherzer, M. T. Greiner, J. Allan, M. Hashagen, G. Weinberg, S. Piccinin, M. Hävecker, A. KnopGericke and R. Schlögl, Surf. Interface Anal., 2016, 48, 261-273.

6 H. G. Sanchez Casalongue, M. L. Ng, S. Kaya, D. Friebel, H. Ogasawara and A. Nilsson, Angew. Chemie Int. Ed., 2014, 53, 7169-7172.

67 T. Reier, D. Teschner, T. Lunkenbein, A. Bergmann, S. Selve, R. Kraehnert, R. Schlogl and P. Strasser, J. Electrochem. Soc., 2014, 161, F876-F882.

R. Kötz, H. Neff and S. Stcki, J. Electrochem. Soc., 1984, 131, 72-77.

V. A. Saveleva, L. Wang, D. Teschner, T. Jones, A. S. Gago, K. A. Friedrich, S. Zafeiratos, R. Schlögl and E. R. Savinova, J. Phys. Chem. Lett., 2018, 9, 3154-3160.

S. J. Freakley, J. Ruiz-Esquius and D. J. Morgan, Surf. Interface Anal., 2017, 49, 794-799.

D. F. Abbott, E. Fabbri, M. Borlaf, F. Bozza, R. Schäublin, M. Nacthegaal, T. Graule and T. J. Schmidt, J. Mater. Chem. A, 2018, 6, 24534-24549.

B.-J. Kim, E. Fabbri, D. F. Abbott, X. Cheng, A. H. Clark, M. Nachtegaal, M. Borlaf, I. E. Castelli, T. Graule and T. J. Schmidt, J. Am. Chem. Soc., 2019, 141, 5231-5240.

T. Pauportè, D. Aberdam, J.-L. Hazemann, R. Faure and D. Robert, J. Electroanal. Chem., 1999, 465, 88-95.

74 Y. Mo, I. C. Stefan, W. Cai, J. Dong, P. Carey and D. A. Scherson, J. Phys. Chem. B, 2002, 106, 3681-3686.

75 M. Hüppauff and B. Lengeler, J. Electrochem. Soc., 1993, 140, 598-602.

6 H. N. Nong, T. Reier, H.-S. Oh, M. Gliech, P. Paciok, T. H. T. Vu, D. Teschner, M. Heggen, V. Petkov, R. Schlögl, T. Jones and P. Strasser, Nat. Catal., 2018, 1, 841-851. 
77 O. Kasian, J. Grote, S. Geiger, S. Cherevko and K. J. J. Mayrhofer, Angew. Chemie Int. Ed., 2018, 57, 2488-2491.

Table 1. Summary of the two catalysts' OER-activity parameters derived from the Tafel plots in Fig. 2b (i.e., prior to the accelerated stress tests), along with their corresponding activity retention at the end of the ASTs' 500 potential cycles.

\begin{tabular}{|c|c|c|c|c|}
\hline & $\begin{array}{l}\text { Tafel slope } \\
\left(\mathrm{mV} \cdot \mathrm{dec}^{-1}\right)\end{array}$ & 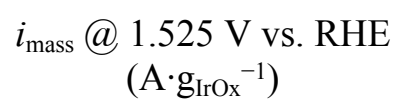 & $\begin{array}{c}U @ 10 \mathrm{~A} \cdot \mathrm{g}_{\mathrm{IrOx}}{ }^{-1} \\
(\mathrm{~V} \text { vs. RHE) }\end{array}$ & $\begin{array}{l}\text { Activity retention } \\
\text { in the AST }(\%)\end{array}$ \\
\hline $\mathrm{IrO}_{\mathrm{x}}-\mathrm{AS}$ & $44 \pm 1$ & $55 \pm 3$ & $1.490 \pm 0.001$ & $55 \pm 3$ \\
\hline $\mathrm{IrO}_{2}-\mathrm{HT}$ & $40 \pm 1$ & $26 \pm 1$ & $1.509 \pm 0.001$ & $70 \pm 5$ \\
\hline
\end{tabular}



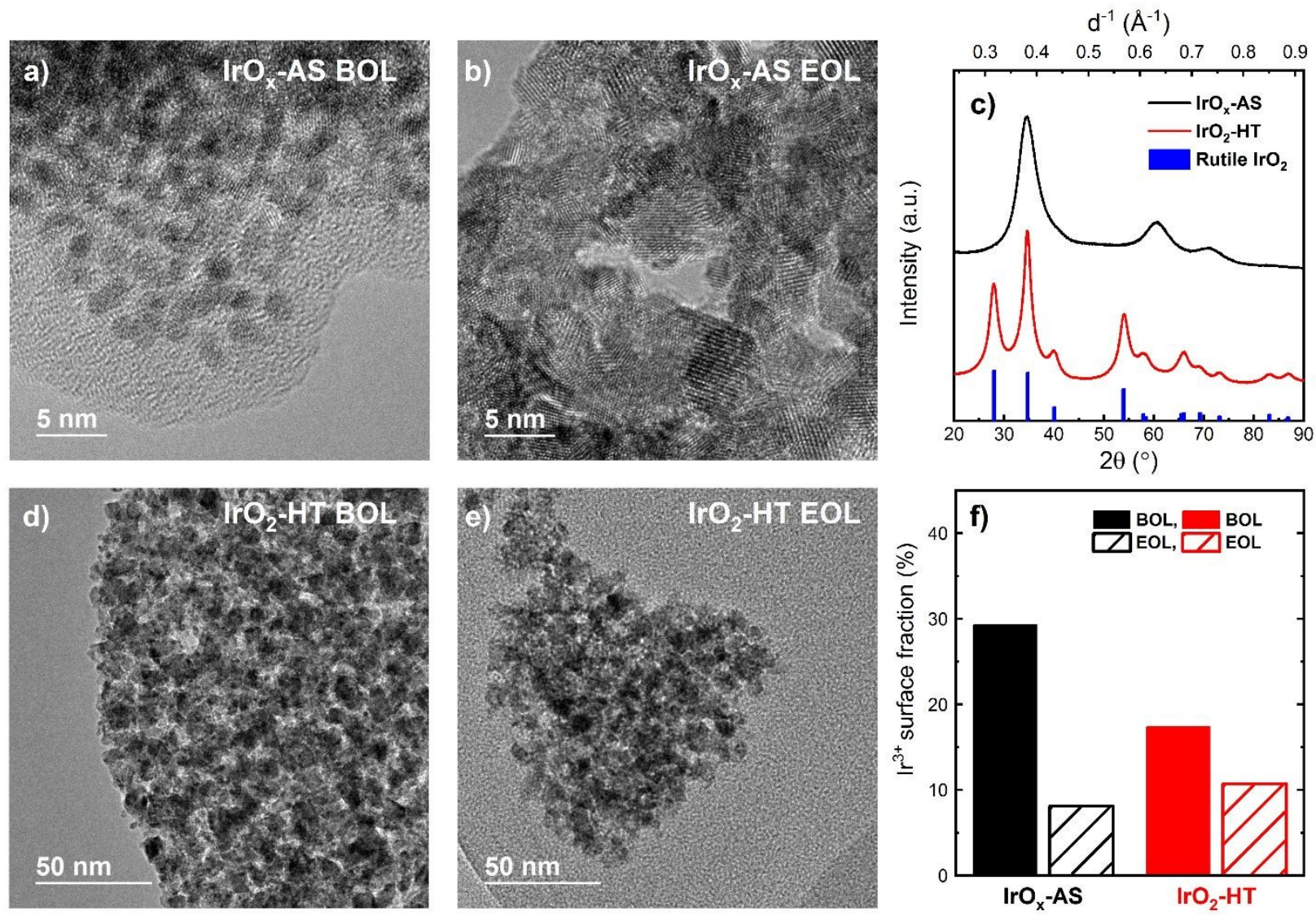

Fig. 1 TEM images of the $\operatorname{IrO}_{x}-\mathrm{AS}(\mathrm{a}, \mathrm{b})$ and $\mathrm{IrO}_{2}-\mathrm{HT}(\mathrm{d}, \mathrm{e})$ catalysts prior to and at the end of the electrochemical accelerated stress test ( $\mathrm{a}$ and $\mathrm{d}$ vs. $\mathrm{b}$ and e, labelled as beginning- vs. end-of-life (BOL, EOL), respectively). Corresponding XRD pattern of the two catalysts in their initial powder state (c), whereby the blue bars refer to the rutile $\mathrm{IrO}_{2}$ model reported in card entry 0019243 of the American mineralogist crystal structure database. ${ }^{61,62}$ Summary of the fractions of $\mathrm{Ir}^{3+}$ on the catalysts' surfaces prior to and after the electrochemical AST, as derived from XPS measurements of the initial powders and postmortem electrodes (BOL vs. EOL, respectively $-\mathrm{f}$ ). 


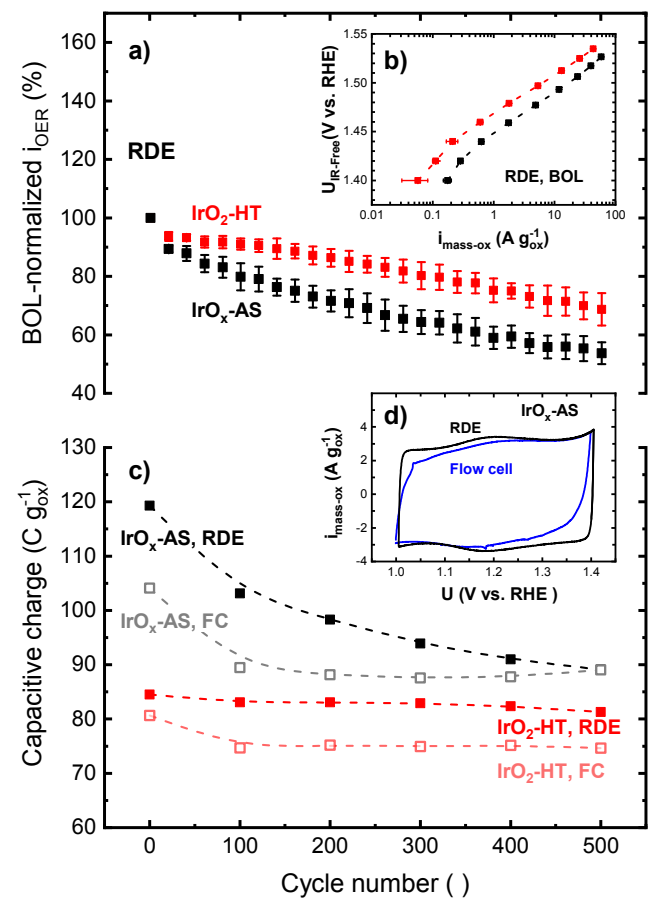

Fig. 2 OER Tafel plots prior to the AST (b) and corresponding, cycle-dependent OER-activity decays (expressed as the mass-normalized current at $1.6 \mathrm{~V}$ vs. RHE normalized with respect to the BOL-value a) derived from $\mathrm{RDE}$ measurements in air-saturated $0.1 \mathrm{M} \mathrm{HClO}$ with oxide loadings of $\approx 100 \mu \mathrm{g}_{\mathrm{IrOx}} \cdot \mathrm{cm}_{\text {geom }}{ }^{-2}$. Comparison of the BOL, mass-normalized capacitive currents recorded (at $10 \mathrm{mV} \cdot \mathrm{s}^{-1}$ ) on $\mathrm{IrO}_{\mathrm{x}}$-AS electrodes in the above RDE-configuration and in the flow cell (FC) used for operando XAS and SAXS measurements (in the latter case, also with air-saturated, $0.1 \mathrm{M} \mathrm{HClO}_{4}$ electrolyte, but using loadings of $\approx 3000 \mu \mathrm{g}_{\mathrm{IrOx}} \cdot \mathrm{cm}_{\text {geom }}{ }^{-2}-\mathrm{d}$ ). Cycle-dependent evolution of the corresponding capacitive charges derived from CVs recorded in the course of the AST, for measurements performed on both catalysts in RDE vs. FC configurations (c). 

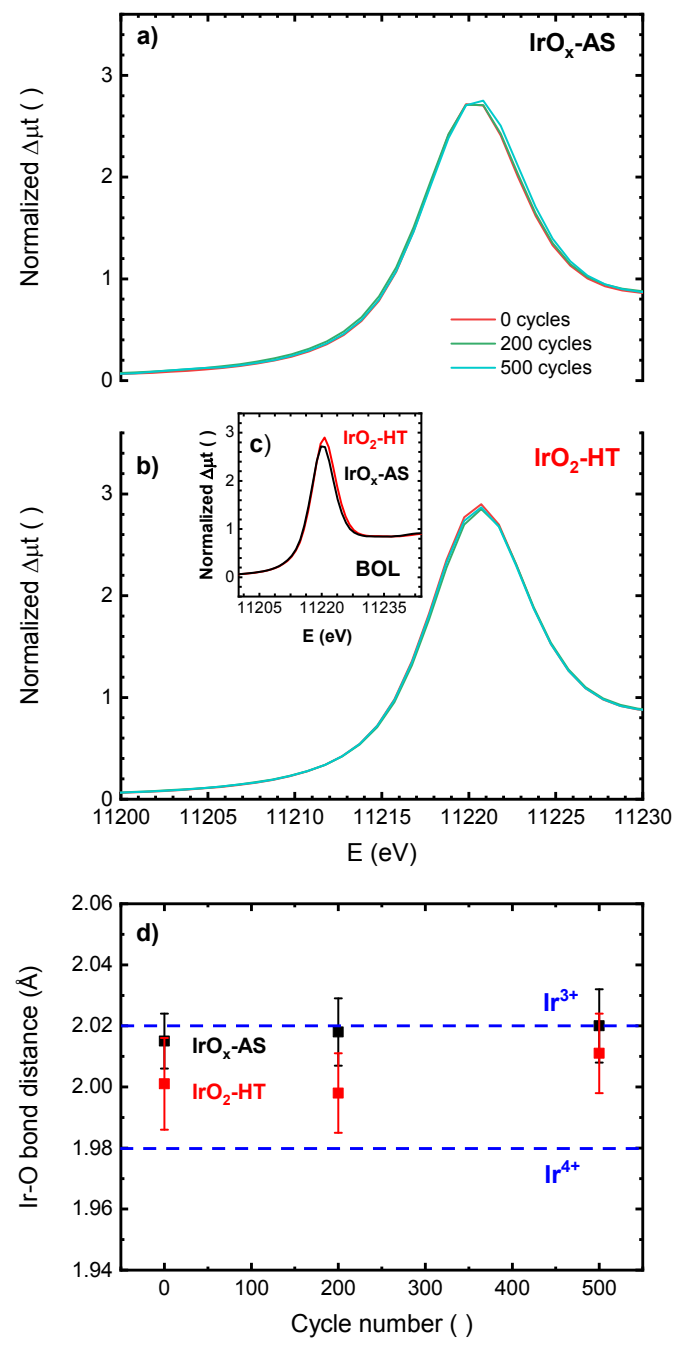

Fig. 3 Cycle-dependent, normalized in situ XANES spectra acquired (at a potential of $1.0 \mathrm{~V}$ vs. RHE) in the course of the AST for $\mathrm{IrO}_{\mathrm{x}}-\mathrm{AS}$ (a) and $\mathrm{IrO}_{2}-\mathrm{HT}$ (b), along with a comparison of the BOL spectra recorded for both catalysts (c). Summary of the Ir-O bond distance values derived from the fits of the corresponding EXAFS spectra as function of the degradation cycles, whereby the dashed lines indicate the

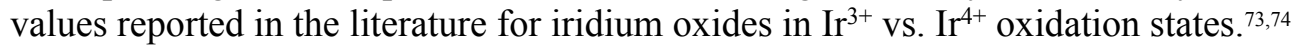



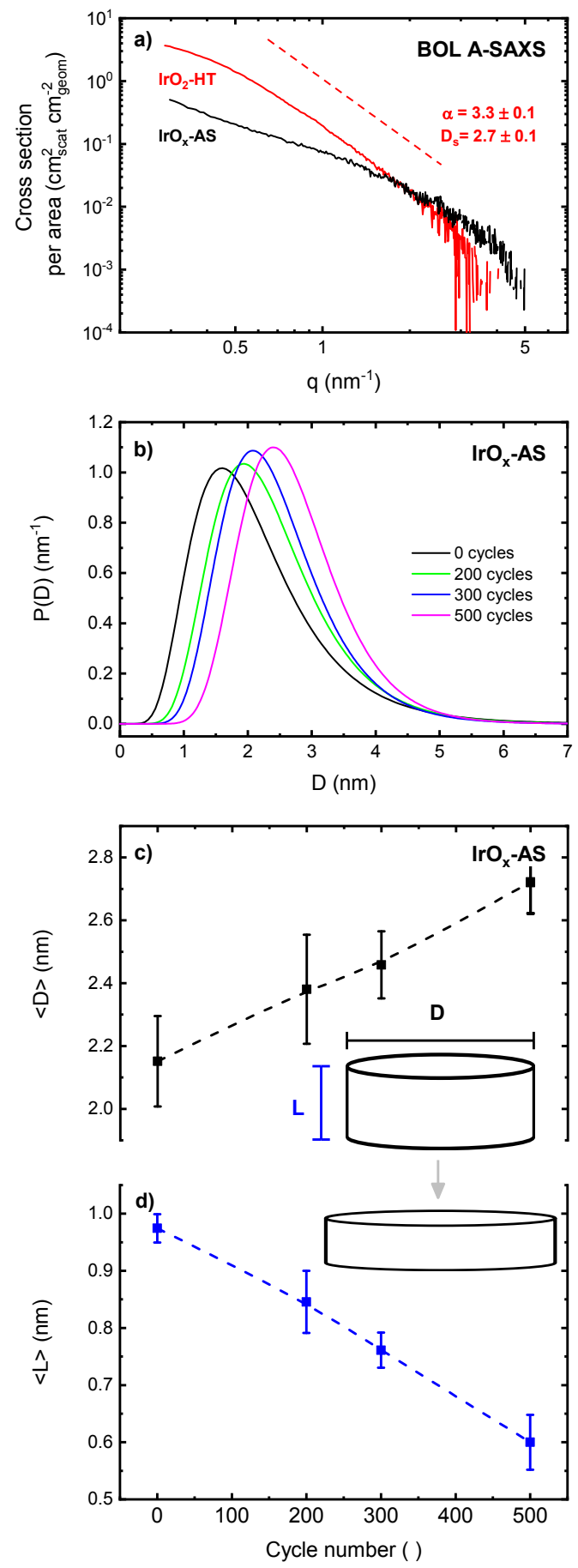

Fig. 4 BOL, in situ A-SAXS curves obtained (at $1.0 \mathrm{~V}$ vs. RHE) on the $\mathrm{IrO}_{\mathrm{x}}-\mathrm{AS}$ and $\mathrm{IrO}_{2}-\mathrm{HT}$ catalysts, whereby the dashed straight line features a slope $(\alpha)$ of 3.3 that correspond to a fractal surface dimension $\left(\mathrm{D}_{\mathrm{s}}\right)$ value of 2.7 for the $\mathrm{IrO}_{2}$-HT catalyst (a). The A-SAXS curves of the $\mathrm{IrO}_{\mathrm{x}}$-AS catalyst were analyzed assuming a disk form factor for which the cycle-dependent evolution of the diameter's log-normal distribution appears plotted in (b). The corresponding variation of the oxide disks' average diameter $(<\mathrm{D}>)$ and thickness $(<\mathrm{L}>)$ in the course of the AST appear plotted in (c) and (d), respectively, and indicate a progressive flattening of the catalyst's disks. 

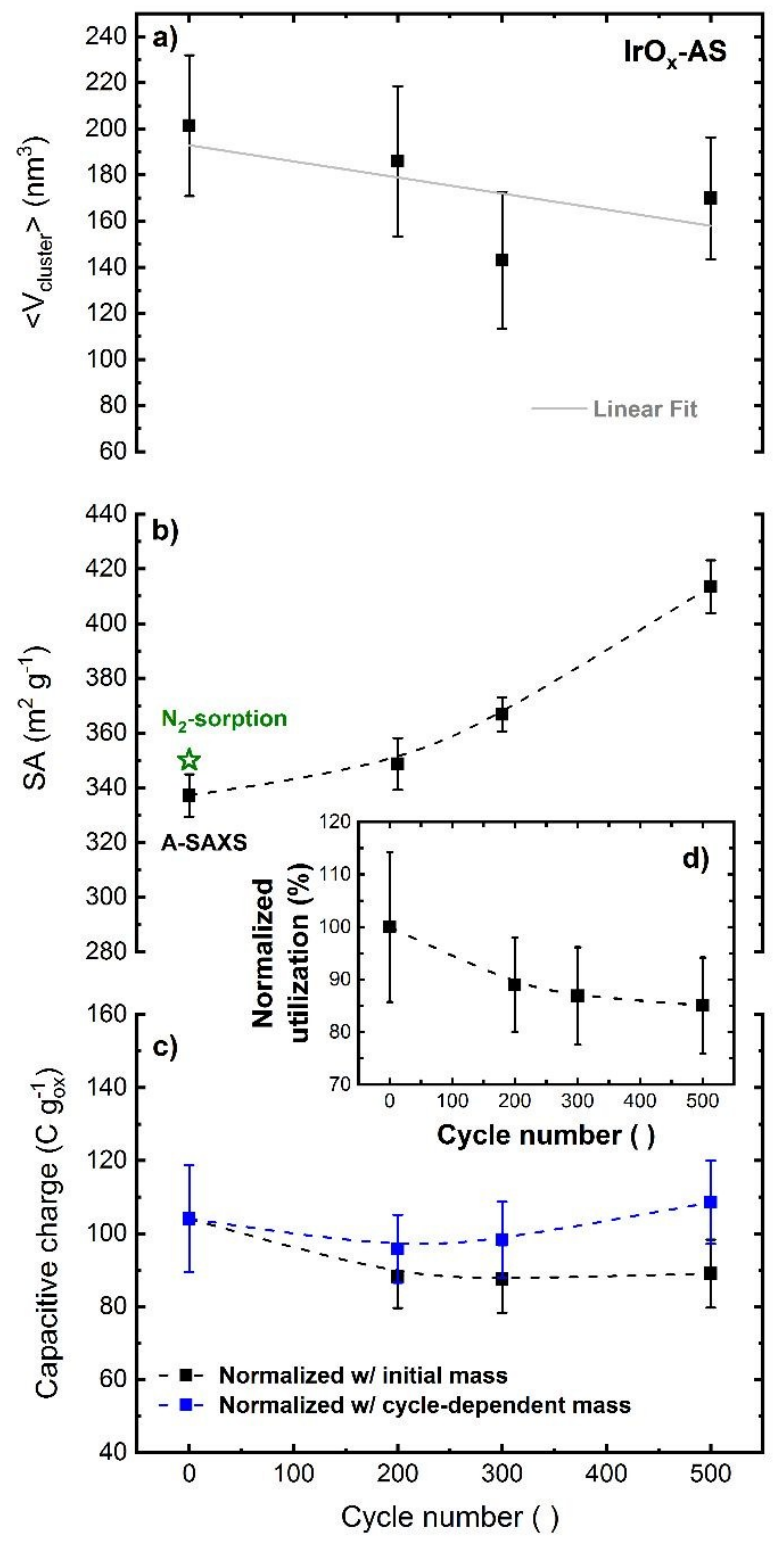

Fig. 5 Results of the fractal analysis of the in situ A-SAXS acquired (at 1.0 V vs. RHE) on the $\mathrm{IrO}_{\mathrm{x}}-\mathrm{AS}$ catalyst in the course of the electrochemical AST. Cycle-dependent evolution of the average cluster volume $\left(\left\langle\mathrm{V}_{\text {cluster }}\right\rangle\right.$, a) and geometrical surface area (SA, b), including the BOL-value derived from a $\mathrm{N}_{2}$-sorption porosimetry measurement performed on the as-synthesized catalyst powder. Comparison of the double layer capacitive charges derived from the CVs recorded in the course of the AST (c), mass-normalized with respect to the BOL-loading (black dots, equivalent to Fig. 2c) or considering the loss of Ir inferred from the decrease of cluster volume / mass reported in panel (a). Panel (d) displays the corresponding, cycledependent evolution of the catalyst layer's normalized utilization, estimated as a quotient among the masscorrected double layer charges in (c) and the SA values in (b). 


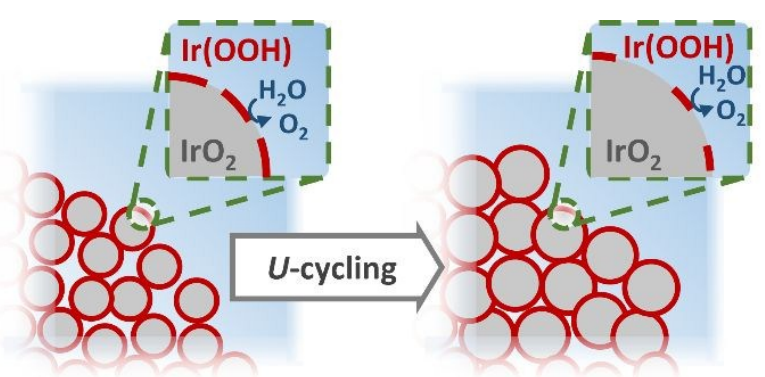

Table of Contents

Operando X-ray techniques allow an unprecedented, quantitative discrimination of the instability mechanisms affecting Ir-oxide catalysts for the evolution of oxygen 